\title{
LA OPERATIVIDAD TURÍSTICA DE LOS ESPACIOS CULTURALES DE ORIGEN INDUSTRIAL EN MADRID. UN ANÁLISIS DE LA OFERTA TURÍSTICA POTENCIAL MEDIANTE INDICADORES
}

\author{
Carmen Hidalgo Giralt* \\ Universidad Autónoma de Madrid \\ Antonio J. Palacios García** \\ Universidad Autónoma de Madrid \\ Vanessa Fernández Chamorro**** \\ Universidad a Distancia de Madrid
}

\section{RESUMEN}

En el municipio de Madrid se han detectado 18 espacios culturales de origen industrial que se integran en la oferta cultural de la ciudad, pero no en sus dinámicas turísticas a pesar de la calidad de sus programas culturales y sus valores históricos y artísticos. Aunque son reconocidos por la sociedad como recursos culturales de referencia no se suelen valorar como recursos turísticos capaces de diversificar la oferta actual. Con el fin de determinar qué factores están limitando su proceso de valorización turística, se han diseñado indicadores para medir aspectos claves de su operatividad turística.

Palabras clave: espacios culturales industriales; recurso cultural; recurso turístico; operatividad turística; indicadores.

Recibido: 28 de junio de 2016

Devuelto para su revisión: 12 de diciembre de 2016

Aceptado: 13 de febrero de 2017

Facultad de Filosofía y Letras. Departamento de Geografía. Universidad Autónoma de Madrid. Campus de Cantoblanco. 28049 MADRID (España).E-mail: carmen.hidalgog@uam.es

** Facultad de Filosofía y Letras. Departamento de Geografía. Universidad Autónoma de Madrid. Campus de Cantoblanco. 28049 MADRID (España).E-mail: antonio.palacios@uam.es

*** Escuela de Ciencias Técnicas e Ingeniería. Universidad a Distancia de Madrid. Ctra. de la Coruña, $\mathrm{km}$. 38,500, Vía de servicio no 15.28400 Collado Villalba. MADRID (España).E-mail: vanessa.fernandez@udima.es 


\title{
Touristic effectiveness in cultural spaces of industrial origin. An analysis of the touristic potentiality using indicators
}

\begin{abstract}
In Madrid municipality have been detected 18 cultural spaces with an industrial origin that are integrated into the cultural offer of the city. But despite their historical and artistic values and the quality of their cultural programs, they are not integrated in the tourist dynamics of Madrid. Industrial heritage is recognized as a cultural resource but in no case are valued as tourist resources capable to increase the tourist offer of the city. In order to determine what factors are limiting the process of tourist valorization, a group of indicators have been designed to analyze key aspects of the tourism operation.
\end{abstract}

Keywords: industrial cultural spaces; cultural resources; touristic resources; touristic operative; indicators.

\section{UNA BREVE CONTEXTUALIZACIÓN. EL PATRIMONIO INDUSTRIAL Y SU INTEGRACIÓN EN LA OFERTA TURÍSTICA DE MADRID}

El número de viajeros registrados en España durante la última década ha experimentado un crecimiento del 31,7\% según la Encuesta de Ocupación Hotelera del Instituto Nacional de Estadística (INE). Se ha pasado de los 70,6 millones de viajeros en el año 2005 a los 93 millones en el 2015. Durante este mismo periodo, el municipio de Madrid refleja un comportamiento similar al contexto nacional. En el año 2005 se alcanzaron los 5,9 millones y en el 2015, los 7,7 millones, lo que supone un crecimiento del $30,5 \%$. En el caso de España, la inestabilidad política de países mediterráneos tradicionalmente competidores como Túnez, Turquía o Egipto explican, entre otros muchos motivos, los buenos datos obtenidos. En el caso del municipio de Madrid la lectura es más compleja. Su papel de capitalidad y región metropolitana junto con su condición de "puerta" entre América y Europa explican la capacidad de Madrid para atraer flujos turísticos (Valenzuela, 2001; 2010). Sin lugar a dudas la oferta cultural y de ocio de la ciudad, así como la calidad de su propuesta museística encabezada por el Triángulo del Arte (Museo del Prado, Museo Thyssen-Bornemisza y Museo Nacional Centro de Arte Reina Sofía) se posicionan como unas de las principales motivaciones de los turistas para visitar la ciudad (Barrado, Palacios e Hidalgo, 2013).

Aunque no se han localizado datos municipales, las cifras registradas en el Anuario de Estadísticas Culturales del Ministerio de Cultura reflejan la importancia del turismo cultural para la Comunidad de Madrid y, por lo tanto, también para el municipio. Los datos revelan que el $10 \%$ de los viajes realizados a dicha comunidad, tanto por los residentes españoles como por los turistas internacionales, tuvieron una motivación cultural. En el primer caso, el gasto realizado por persona asciende a 425 euros, mientras que en el segundo alcanza los 1.060. Teniendo en cuenta que una parte destacable del turismo de la región deriva de una motivación cultural y que el gasto que realizan los turistas es considerable, las acciones de valoración turística del patrimonio cultural, 
el diseño de productos turísticos especializados en bienes culturales y el desarrollo de nuevas modalidades de turismo cultural deberían constituir un objetivo prioritario de los agentes públicos y privados con el fin de incrementar y diversificar la oferta turística de la ciudad. Sin embargo, la realidad resulta diferente especialmente para el patrimonio cultural objeto de estudio en esta investigación, el patrimonio industrial. En los próximos apartados, se analizará el papel que esta modalidad de bienes culturales juega actualmente en las dinámicas turísticas de la ciudad, se analizará su grado de integración en la oferta turística del municipio de Madrid y se incidirá en su potencial como recurso cultural y turístico.

Pero ¿qué se entiende por patrimonio industrial? En la revisión del Plan Nacional de Patrimonio Industrial elaborado por el Instituto de Patrimonio Cultural (IPCE) en el año 2011, el patrimonio industrial se define como "el conjunto de bienes muebles, inmuebles y sistemas de sociabilidad relacionados con la cultura del trabajo que han sido generados por las actividades de extracción, de transformación, de transporte, de distribución y gestión generadas por el sistema económico surgido de la Revolución Industrial". El plan distingue tres tipos de elementos industriales: bienes inmuebles (elementos industriales, conjuntos industriales, paisajes industriales y sistemas y redes industriales), bienes muebles (artefactos, utillajes, mobiliario y accesorios del entorno social del trabajo y archivos) y bienes inmateriales (memoria de la industria). Esta noción tan amplia de patrimonio industrial ha permitido integrar en la presente investigación tipologías diversas de bienes que abarcan desde la industria agroalimentaria hasta el transporte, pasando por la producción energética o la extracción y distribución de aguas. En este documento se plantea un concepto dinámico del patrimonio industrial al diseñar una serie de propuestas relacionadas con su conservación activa entre las que destaca su posible integración en experiencias de turismo industrial, tema de estudio de esta investigación.

El desarrollo industrial de Madrid, que supone el origen del patrimonio industrial, se inició en el siglo XVIII con la construcción de las manufacturas reales impulsadas por la nueva dinastía borbónica (Revilla y Ramos, 2008). Durante el siglo siguiente, el crecimiento urbano generó una demanda de bienes agroalimentarios y de transporte a los que se sumó la necesidad de canalizar el agua que abastecía a la población. Esta tendencia constructiva continuó durante la primera mitad del siglo XX e incluso se acentuó durante el periodo 1950-1970 como consecuencia de la política autárquica franquista durante la cual Madrid se posicionó como un polo industrial de referencia nacional. En las dos décadas posteriores, la crisis económica y la recesión de la actividad industrial generaron la reubicación de las instalaciones en zonas urbanas periféricas iniciándose, de esta manera, la problemática de los vacíos industriales en la ciudad estudiada en profundidad por Pardo (2004). Paradójicamente, durante este último periodo en el que una parte importante de las infraestructuras industriales fueron destruidas o desplazadas fuera del núcleo urbano, las administraciones públicas comenzaron a proteger determinados edificios industriales por sus valores culturales de carácter excepcional, llegándose a declarar 15 Bienes de Interés Cultural (BIC) (Cuadro 1). Además, el Plan General de Ordenación Urbana (PGOU) de Madrid de 1997 procedió a la catalogación de 7 elementos más (Cuadro 2). 
En el caso de Madrid, la protección administrativa del patrimonio industrial ha supuesto un paso fundamental para su transformación en equipamientos culturales ${ }^{1}$. Sin embargo, a pesar de la excepcionalidad cultural del patrimonio industrial de la ciudad y de su éxito aparente como recurso cultural, su integración en la oferta turística es prácticamente nula. Hidalgo y Palacios (2016) analizaron parcialmente la proyección turística de este tipo de bienes culturales señalando como principales causas de esta situación las siguientes razones:

- El patrimonio industrial de la ciudad no aparece reflejado en el Plan Estratégico de Turismo. Ciudad de Madrid (2012-2015) diseñado por el anterior equipo municipal. Actualmente, no hay ningún plan de turismo en activo en la ciudad.

- La promoción turística del patrimonio industrial a través de los portales web oficiales es muy limitada. El portal de Turismo de España hace referencia tan solo a los mercados tradicionales como el de San Miguel como ejemplos de bienes industriales, aunque en ningún caso se alude a su origen. Por su parte, la web oficial de turismo de la Comunidad de Madrid "Madrid About You", en la actualidad, "Region of Madrid", dedica una guía al Madrid Contemporáneo incluyendo algunos edificios industriales pero sin profundizar en sus características. Finalmente, la web del Ayuntamiento de Madrid promociona los usos culturales de antiguos espacios industriales pero sin incidir en sus usos originales.

- Los productos turísticos estructurados en torno al patrimonio industrial son prácticamente inexistentes. Los autores detectaron tan solo dos itinerarios, la Ruta del Patrimonio Industrial, diseñada por la Asociación de Guías de Turismo de Madrid (APIT); y, Lavapiés, un Barrio Obrero, creada por la empresa Madrid Original.

\section{Cuadro 1 \\ ELEMENTOS DEL PATRIMONIO INDUSTRIAL MADRILEÑO CATALOGADOS COMO BIC}

\begin{tabular}{|l|c|c|c|c|}
\hline \multirow{2}{*}{ Denominación BIC } & \multicolumn{2}{c|}{ Declaración BIC } & \multicolumn{2}{c|}{ Protección PGOU (1997) } \\
\cline { 2 - 5 } & Categoría & Año & Nivel & Protección \\
\hline 1. Real Fábrica de Aguardientes y Naipes & Monumento & 1977 & Nivel 1 & Singular \\
\hline 2. Estación de Príncipe Pío & Monumento & 1977 & Nivel 1 & Singular \\
\hline 3. Edificio ABC (Blanco y Negro) & Monumento & 1977 & Nivel 2 & Estructural \\
\hline 4. Estación de Atocha & Monumento & 1977 & Nivel 1 & Singular \\
\hline 5. Actual estación de Servicio Gesa, S.L & Monumento & 1977 & Sin protección \\
\hline 6. Central térmica de la Ciudad Universitaria de Madrid & Monumento & 1977 & \multicolumn{2}{|c|}{ Sin protección } \\
\hline 7. Segundo depósito del Canal de Isabel II & Monumento & 1977 & \multicolumn{2}{|c|}{ Sin protección } \\
\hline 8. Estación de Delicias & Monumento & 1981 & Nivel 1 & Singular \\
\hline
\end{tabular}

1 Se entiende como equipamiento cultural como "el conjunto de edificios que disponen de los medios técnicos y de los instrumentos necesarios para ofrecer al ciudadano una serie de servicios o actividades culturales. La calidad de uso de estos espacios vendrá dada por su acertada ubicación urbana y por la calidad del espacio público en el que se sitúan (Junta de Andalucía, 2006). 


\begin{tabular}{|c|c|c|c|c|}
\hline 9. Mercado de San Miguel & Monumento & 1982 & Nivel 1 & Singular \\
\hline 10. Fábrica de cervezas El Águila & Monumento & 1990 & Nivel 1 & Singular \\
\hline 11. Fábrica OSRAM & Monumento & 1991 & Nivel 1 & Singular \\
\hline 12. Primer depósito del Canal de Isabel II & Monumento & 1993 & Nivel 3 & Parcial \\
\hline $\begin{array}{l}\text { 13. Central elevadora y primer depósito del Canal de } \\
\text { lsabel II }\end{array}$ & Monumento & 1993 & Nivel 1 & Singular \\
\hline 14. Real Fábrica de Tapices & Monumento & 2006 & Nivel 1 & Integral \\
\hline 15. Antigua central eléctrica de Pacífico & Monumento & 2012 & Nivel 1 & Singular \\
\hline
\end{tabular}

Fuente: elaboración propia.

\section{Cuadro 2 \\ PROTECCIÓN DE LOS ELEMENTOS DE PATRIMONIO INDUSTRIAL DE MADRID NO DECLARADOS BIC}

\begin{tabular}{|c|c|c|c|c|}
\hline \multirow{2}{*}{ Denominación BIC } & \multicolumn{2}{|c|}{ Declaración BIC } & \multicolumn{2}{|c|}{ Protección PGOU (1997) } \\
\hline & Categoría & Año & Nivel & Protección \\
\hline 1. Central eléctrica del Mediodía & \multicolumn{2}{|c|}{ Sin protección } & Nivel 3 & Parcial \\
\hline 2. Serrería de los Belgas & \multicolumn{2}{|c|}{ Sin protección } & Nivel 2 & Estructural \\
\hline $\begin{array}{l}\text { 3. Fábrica al Vapor de Colores, Barnices y Hielo Vda. e } \\
\text { Hijos de Casimiro Mahou }\end{array}$ & \multicolumn{2}{|c|}{ Sin protección } & Nivel 3 & Parcial \\
\hline 4. Depósito de aguas del Canal de Isabel II & \multicolumn{2}{|c|}{ Sin protección } & Nivel 3 & Ambiental \\
\hline 5. Fábrica de galletas Pacisa & \multicolumn{2}{|c|}{ Sin protección } & Nivel 3 & Parcial \\
\hline 6. Matadero municipal y Mercado de ganados & \multicolumn{2}{|c|}{ Sin protección } & Nivel 2 & Estructural \\
\hline 7. Talleres Renfe (Atocha) & \multicolumn{2}{|c|}{ Sin protección } & Nivel 1 & Integral \\
\hline
\end{tabular}

Fuente: elaboración propia.

Con el objetivo de complementar estas afirmaciones, se ha realizado un pre-test donde se ha preguntado a 16 operadores turísticos del municipio de Madrid a través de una encuesta on-line elaborada en Google Forms ${ }^{2}$ sobre la creación de productos turísticos relacionados con el patrimonio industrial. Aunque es una muestra no representativa puesto que el número de respuestas ha sido bajo, tan solo el $25 \%$, los resultados se pueden considerar orientativos permitiendo obtener una visión más completa de la realidad al obtener la perspectiva de los agentes privados. Los resultados obtenidos fueron altamente coincidentes, el $75 \%$ de los entrevistados había diseñado algún producto turístico relacionado con el patrimonio industrial, principalmente circuitos no especializados o visitas a centros culturales de origen industrial (Matadero, Caixa Fórum Madrid, etc.) pero el 66,6\% de los operadores dejaron de ofertar el producto puesto que la demanda no era suficiente y no resultaba interesante para los clientes. No obstante, a pesar de ello se manifestaban interesados en poner en marcha nuevamente productos estructurados en torno al patrimonio industrial.

Atendiendo a estos aspectos, se puede deducir que el patrimonio industrial no se integra en la planificación turística de la ciudad a pesar de su alta representatividad cultural. Los

2 https://docs.google.com/forms/d/1_f5sx81Hcu50vczEB3JcIDtIm5ZzmD7DwszN8Rz7ASs/formResponse. 
canales de promoción oficiales apenas aluden a unos cuantos ejemplos de bienes industriales sin ningún tipo de referencia histórica y no existen productos turísticos diseñados por los operadores que permitan desarrollar actividades de comercialización. Por lo tanto, la dinamización turística del patrimonio industrial resulta claramente insuficiente. Dicho de otro modo, la ciudad no está interpretando los elementos de patrimonio industrial como recursos turísticos (Benito del Pozo, 2016). Precisamente, esta situación tan negativa hacia la valoración del patrimonio industrial, se manifiesta como el punto de partida de la presente investigación. Se pretende determinar las razones por las que dicho patrimonio que opera como un recurso cultural en la ciudad no lo hace como uno turístico. Para profundizar en estos aspectos se analizará el grado de operatividad turística de los espacios culturales de origen industrial determinando qué factores están favoreciendo su integración en la oferta turística de la ciudad y en qué medida; y, en contraposición, cuáles la están obstaculizando y cómo.

\section{LA OPERATIVIDAD TURÍSTICA DEL PATRIMONIO INDUSTRIAL}

Durante más de dos décadas los especialistas españoles han investigado las relaciones existentes entre el patrimonio industrial y el turismo en nuestro país. Una revisión exhaustiva de la literatura científica (Llurdés i Coit, 1999; Cañizares, 1999; Benito del Pozo, 2002; Pardo, 2004; Valenzuela et $a l ., 2008$ ) permite concluir que el patrimonio industrial puede transformarse en un importante recurso cultural como consecuencia de sus valores históricos y artísticos excepcionales e, incluso, en un recurso turístico si ha sido acondicionado previamente para ello (Barrado, 2011). No obstante, su integración en la oferta turística de los destinos a través de una estructura fuerte de productos es prácticamente inexistente por motivos diferentes como, por ejemplo, el desconocimiento que la sociedad tiene sobre este tipo de patrimonio cultural, la débil promoción que desde las administraciones públicas se otorga a estos bienes culturales, o la escasa cooperación institucional que dificulta la puesta en marcha de proyectos y planes específicos (Caamaño, 2011). Aunque se han puesto en marcha algunas acciones para promocionar y comercializar productos conjuntamente, como es el caso de la "Red Española de Turismo Industrial" (RETI), solo podríamos hablar de éxito en Cataluña donde opera la "Xarxa de Turime Industrial de Catalunya" (XATIC). A estas dos iniciativas se unirá en breve la "Asociación de Operadores Turísticos de Turismo Industrial" (AOIT), una red de agentes turísticos que tiene como objetivo la creación de productos turísticos basados en el patrimonio industrial con los que se trata de dar un vuelco a esta situación.

En el caso de Madrid, la literatura científica que analiza la situación del patrimonio industrial desde un punto de vista turístico resulta escasa, aunque refleja fielmente la situación anteriormente descrita. La ciudad posee un patrimonio industrial relevante que ha sido objeto de estudio de diferentes especialistas en la materia (Fernández y Caballero, 2004; Pardo, 2006; Olivares, 2013). Gran parte de este patrimonio se ha transformado en espacios culturales. Hidalgo y Palacios (2016) analizaron los nuevos usos del patrimonio industrial madrileño declarado BIC concluyendo que el $73 \%$ de los casos analizados poseía una funcionalidad diferente a la planificada en su origen y, de este porcentaje, el $47 \%$ habían sustituido su actividad productiva tradicional por una funcionalidad de tipo cultural. Los autores señalaron que una parte relevante del patrimonio industrial de la ciudad se está transformando 
en contenedores culturales que dinamizan la oferta cultural a través de estrategias de gestión que, por su carácter innovador, incluso han sido seleccionadas como buenas prácticas por el Plan Estratégico de Cultura de Madrid -PECAM- (2012-2015). Algunos de estos elementos culturales como, por ejemplo, la Real Fábrica de Tapices, la antigua Estación de Chamberí, la Nave de Motores de Pacífico o la Fábrica de Cervezas "El Águila”, han sido incluidos en el proyecto cultural "100 Elementos del patrimonio industrial en España", subvencionada por el Ministerio de Educación, Cultural y Deporte (TICCIH, 2016). Sin embargo, a pesar de la excepcionalidad cultural de este patrimonio y de su éxito aparente como recurso cultural, su integración en la oferta turística de la ciudad es prácticamente nula.

Para medir el grado de operatividad turística del patrimonio industrial de la ciudad, es decir, determinar qué elementos favorecen la dinamización turística de un bien cultural y en qué grado, se han diseñado una propuesta de indicadores. El recurso a los mismos constituye una metodología habitual en la gestión de los destinos que permite alcanzar una visión general de la realidad y adoptar decisiones concretas en base a los resultados obtenidos (Sancho y García, 2006). Lamentablemente, no se han detectado investigaciones que cuantifiquen el análisis de la operatividad turística de los bienes industriales a través de indicadores, lo que ha obligado a tomar como referencia estudios que, aunque centrados en el análisis de destino, no se aplican específicamente a los espacios culturales de origen industrial. Por lo tanto, resulta indispensable destacar que los indicadores propuestos ni son universales, ni se encuentran consensuados por el colectivo científico. Es de esperar que investigaciones similares puedan verificar la idoneidad de los mismos.

El análisis de la sostenibilidad de los destinos es un área frecuente de aplicación de indicadores. Además de los trabajos desarrollados por el Ministerio de Medio Ambiente (Ministerio de Medio Ambiente, 2003) y por la Organización Mundial del Turismo (Organización Mundial del Turismo, 1995), destacan los artículos de Pardo (2014) que, a partir de cuatro componentes generales y 23 indicadores elabora un índice sintético de desarrollo sostenible (ISDS), aplicado a varios estudios de caso, o el artículo elaborado por Sancho y García (2006) en el que presentan un estudio comparativo de destinos turísticos enfrentando los resultados obtenidos a través de los indicadores objetivos con los resultados de un análisis de corte más subjetivo con el fin de determinar la sostenibilidad existente. De su propuesta de indicadores se han tomado como referencia para esta investigación los relacionados con la accesibilidad y los recursos patrimoniales, puesto que valoran la proximidad del transporte público al destino, así como las normativas existentes sobre la protección del patrimonio cultural y natural ubicado en su área. Interesante también resulta el estudio de Blancas et al. (2010) centrado en la aplicación de indicadores sintéticos en destinos andaluces con el fin de valorar su sostenibilidad. En este caso, se han prestado especial atención a los ítems relacionados con la conservación del patrimonio cultural y la mejora del paisaje urbano.

Para completar la elaboración de los indicadores, también se han tomado como referencia trabajos vinculados con el inventario de recursos, técnica definida por Díaz (2010) como una "relación de los recursos existentes en un territorio, en la cual se identifican, clasifican y describen según la metodología seleccionada". Los inventarios resultan esenciales en la planificación de los destinos, son herramientas esenciales que permiten identificar y diagnosticar la realidad de los recursos turísticos para, posteriormente, establecer 
propuestas coherentes de actuación. La OMT o la Organización de Estados Americanos (OEA) fueron algunas de las primeras instituciones en elaborar metodologías de trabajo mediante diferentes técnicas de registro. En España resultan destacables los trabajos de Leno (1993) así como los de López (1998) y Callizo y Lacosta (1999). Los trabajos de inventario se han incrementado considerablemente en los últimos años pero no han sido validados desde un punto de vista científico, lo que limita la posibilidad de realizar, por ejemplo, estudios comparativos entre destinos turísticos.

\section{HIPÓTESIS, OBJETIVOS Y METODOLOGÍA DE TRABAJO}

Resultan representativos los casos de elementos del patrimonio industrial que tras el cese de su actividad han sido transformados en espacios culturales que incrementan la oferta cultural de Madrid. A pesar de su innegable valor patrimonial, su ubicación estratégica en la ciudad y la calidad de los eventos culturales que programan, su integración en la dinámica turística urbana como producto turístico se revela muy limitada, como, por otro lado, señala la bibliografía especializada. La hipótesis que se maneja en esta investigación apunta a que existen determinados factores que favorecen la operatividad turística de los espacios culturales mientras que otros ahogan la transformación de estos recursos culturales en productos turísticos y por lo tanto, restringen su integración en la oferta turística de la ciudad pero ¿qué factores son éstos? ¿Qué peso tienen en la operatividad turística de los espacios culturales de origen industrial? ¿Pueden ser cuantificables? ¿Son capaces de explicar la realidad turística de estos recursos culturales? Con el fin de aclarar estos aspectos, esta investigación tiene como objetivo principal analizar la operatividad turística de los espacios culturales de origen industrial mediante la aplicación de una serie de indicadores para determinar qué factores están obstaculizando su transformación en productos turísticos y su integración en las dinámicas turísticas de la ciudad.

Para alcanzar estos objetivos, en este estudio se plantea una metodología de trabajo basada en un análisis estadístico descriptivo de indicadores. Se trata de 20 ítems (Cuadro 3) que, divididos en 5 grandes grupos (accesibilidad, afecciones legales, información web, paisaje urbano y potencial turístico), se aplican a los 18 espacios culturales de origen industrial inventariados y caracterizados en esta investigación. Con el primer bloque, "accesibilidad", se pretende determinar el grado de accesibilidad del transporte público y privado al espacio cultural, así como la posibilidad de aparcar gratuitamente en las proximidades. Con el conjunto de indicadores "afecciones legales" se gradúa la protección administrativa del patrimonio industrial, así como su integración en la planificación turística y cultural de la ciudad. El bloque "información web" evalúa los portales "on-line" de los espacios culturales, no solo si sus contenidos son básicos y avanzados sino también si desarrollan actividades comerciales a través de la web. Mediante los indicadores de "paisaje urbano", se analiza la relación del espacio cultural con el paisaje urbano que le rodea, así como la proximidad a otros espacios culturales de origen industrial. Finalmente, "potencial turístico" permite determinar la relación del espacio cultural con elementos claves de la oferta turística como son la oferta turística complementaria, la promoción y comercialización turística público-privada o su proximidad a los recursos turísticos más representativos de la ciudad. 


\section{Cuadro 3 GRUPO DE INDICADORES Y CRITERIOS DE PUNTUACIÓN}

\begin{tabular}{|c|c|c|}
\hline \multirow{4}{*}{ Accesibilidad } & Acceso al tráfico rodado & $\begin{array}{l}\text { Alto (3): Sin limitaciones; Medio (2): Limitaciones leves; Bajo (1): } \\
\text { Limitaciones severas; Nulo (0): No hay limitaciones. }\end{array}$ \\
\hline & Cercanía al transporte público & $\begin{array}{l}\text { Alto (3): Menos de } 1 \mathrm{~km} \text {; Medio (2): Más de } 2 \mathrm{Km} \text {; Bajo (1): Más de } \\
3 \mathrm{~km} \text {; Nulo (0): No hay transporte público. }\end{array}$ \\
\hline & Aparcamiento gratuito próximo & $\begin{array}{l}\text { Alto (3): Sin limitaciones; Medio (2): Limitaciones leves; Bajo (1): } \\
\text { Limitaciones severas; Nulo (0): No hay limitaciones. }\end{array}$ \\
\hline & Cercanía a nudos de transporte & $\begin{array}{l}\text { Alto (3): Menos de } 1 \mathrm{~km} \text {; Medio (2): Más de } 2 \mathrm{Km} \\
\text { Bajo (1): Más de } 3 \mathrm{~km} \text {; Nulo (0): No se encuentra próximo. }\end{array}$ \\
\hline \multirow{4}{*}{$\begin{array}{l}\text { Afecciones } \\
\text { legales }\end{array}$} & Grado de protección municipal & $\begin{array}{l}\text { Alto (3): Nivel 3; Medio (2): Nivel 2; Bajo (1): Nivel 1; Nulo (0): } \\
\text { Sin protección. }\end{array}$ \\
\hline & Grado de protección estatal & Alto (3): BIC; Nulo (0): Sin declaración. \\
\hline & $\begin{array}{l}\text { Integración del espacio cultural en } \\
\text { planes turísticos }\end{array}$ & $\begin{array}{l}\text { Alto (3): Integración total; Medio (2): Integración media; Bajo (1): } \\
\text { Integración baja; Nulo (0): Sin integración. }\end{array}$ \\
\hline & $\begin{array}{l}\text { Integración del espacio cultural en } \\
\text { planes culturales }\end{array}$ & $\begin{array}{l}\text { Alto (3): Integración total; Medio (2): Integración media; Bajo (1): } \\
\text { Integración baja; Nulo (0): Sin integración. }\end{array}$ \\
\hline \multirow{4}{*}{ Información web } & Información web & $\begin{array}{l}\text { Alto (3): Portal propio; Medio (2): Portal corporativo; Bajo (1): } \\
\text { Presencia informativa en una web; Nulo (0): Sin presencia. }\end{array}$ \\
\hline & Información web básica & $\begin{array}{l}\text { Alto (3): Información muy adecuada; Medio (2): Información } \\
\text { adecuada; Bajo (1): Información insuficiente; Nulo (0): Sin } \\
\text { información. }\end{array}$ \\
\hline & Información web avanzada & $\begin{array}{l}\text { Alto (3): Información muy adecuada; Medio (2): Información } \\
\text { adecuada; Bajo (1): Información insuficiente; Nulo (0): Sin } \\
\text { información. }\end{array}$ \\
\hline & Posibilidad de e-commerce & $\begin{array}{l}\text { Alto (3): Herramientas avanzadas de comercio electrónico; Medio } \\
\text { (2): Herramientas habituales de comercio electrónico; Bajo (1): } \\
\text { Alguna posibilidad de comercio electrónico; Nulo (0): Sin comercio } \\
\text { electrónico. }\end{array}$ \\
\hline \multirow{4}{*}{ Paisaje urbano } & $\begin{array}{l}\text { Rehabilitación de las edificaciones } \\
\text { integradas en el espacio cultural }\end{array}$ & $\begin{array}{l}\text { Alto (3): Rehabilitación integral incluyendo el espacio; Medio (2): } \\
\text { Rehabilitación integral de los edificios; Bajo (1): Rehabilitación } \\
\text { parcial de los edificios; Nulo (0): Sin rehabilitación. }\end{array}$ \\
\hline & Mejora del espacio urbano próximo & $\begin{array}{l}\text { Alto (3): Espacio altamente mejorado; Medio (2): Espacio mejorado; } \\
\text { Bajo (1): Espacio parcialmente mejorado: Nulo (0): Espacio sin } \\
\text { mejorar. }\end{array}$ \\
\hline & $\begin{array}{l}\text { Proximidad a otros espacios } \\
\text { culturales de origen industrial }\end{array}$ & $\begin{array}{l}\text { Alto (3): Menos de } 1 \mathrm{~km} \text {; Medio (2): Más de } 2 \mathrm{Km} \text {; Bajo (1): Más de } \\
3 \mathrm{~km} \text {; Nulo (0): No se encuentran en las proximidades }\end{array}$ \\
\hline & $\begin{array}{l}\text { Grado de integración del espacio } \\
\text { cultural en el ámbito urbano }\end{array}$ & $\begin{array}{l}\text { Alto (3): Integración alta; Medio (2): Integración media; Bajo (1): } \\
\text { Integración baja; Nulo (0): Sin integración. }\end{array}$ \\
\hline \multirow{4}{*}{$\begin{array}{l}\text { Potencial } \\
\text { turístico }\end{array}$} & $\begin{array}{l}\text { Proximidad del espacio cultural a } \\
\text { los principales atractivos turísticos } \\
\text { de la ciudad }\end{array}$ & $\begin{array}{l}\text { Alto (3): Menos de } 1 \mathrm{~km} \text {; Medio (2): Más de } 2 \mathrm{Km} \text {; Bajo (1): Más de } \\
3 \mathrm{~km} \text {; Nulo (0): No se encuentran en las proximidades }\end{array}$ \\
\hline & $\begin{array}{l}\text { Proximidad de oferta } \\
\text { complementaria turística de calidad }\end{array}$ & $\begin{array}{l}\text { Alto (3): Menos de } 1 \mathrm{~km} \text {; Medio (2): Más de } 2 \mathrm{Km} \text {; Bajo (1): Más de } \\
3 \mathrm{~km} \text {; Nulo (0): No se encuentran en las proximidades }\end{array}$ \\
\hline & $\begin{array}{l}\text { Grado de promoción a través de } \\
\text { organismos públicos }\end{array}$ & $\begin{array}{l}\text { Alto (3): Promoción alta; Medio (2): Promoción media; Bajo (1): } \\
\text { Promoción baja; Nulo (0): Sin promoción. }\end{array}$ \\
\hline & $\begin{array}{l}\text { Comercialización del espacio } \\
\text { cultural a través de organismos } \\
\text { públicos y/o privados }\end{array}$ & $\begin{array}{l}\text { Alto (3): Comercialización alta; Medio (2): Comercialización media; } \\
\text { Bajo (1): Comercialización baja; Nulo (0): Sin comercialización. }\end{array}$ \\
\hline
\end{tabular}

Fuente: elaboración propia. 
Estos indicadores han sido diseñados ex profeso ya que, como se ha señalado anteriormente, no se han detectado investigaciones en las que se utilicen indicadores de operatividad turística susceptibles de ser aplicados, aunque sí se han tenido en cuenta otras metodologías próximas al turismo sostenible y al inventario y evaluación de los recursos turísticos. Una vez aplicados a los casos seleccionados, se ha procedido a realizar un estudio estadístico descriptivo tomando como referencia las puntuaciones obtenidas en una matriz de operatividad turística. Este análisis, complementado con material gráfico (cuadros, gráficos y figuras), ha permitido realizar un diagnóstico de la situación, así como perfilar una serie de propuestas de mejora.

\section{LOS ESPACIOS CULTURALES DE ORIGEN INDUSTRIAL MADRILEÑOS}

Con el objetivo de profundizar en el conocimiento de los espacios culturales de origen industrial del municipio de Madrid se ha realizado un inventario no sistemático, previa revisión de la bibliografía especializada (Candela, Castillo y López, 2002; López y Candela, 2002; Candela, 2006; Pardo, 2006), apoyado por trabajo de campo. Se han registrado un total de 18 equipamientos culturales que han sido divididos en 6 categorías en función de su naturaleza. Para ello, se ha tomado como referencia la clasificación de Del Álamo (2016) que divide los equipamientos culturales en cinco categorías: centro de cultura contemporánea; sala de exposiciones; museos; biblioteca y archivos; y teatro. A esta clasificación se ha sumado la opción de "jardín" para poder incluir a la "Estación de Atocha", también considerado un espacio cultural de origen industrial (Figura 1 y Cuadro 4).

\section{Figura 1 \\ MAPA DE LOCALIZACIÓN DE LOS ESPACIOS CULTURALES DE ORIGEN INDUSTRIAL}

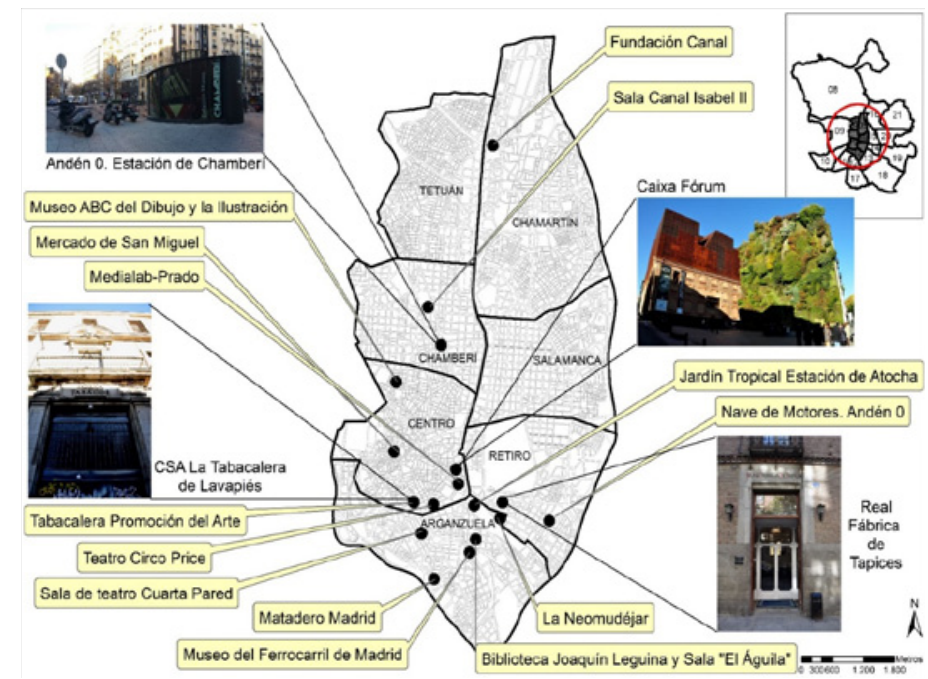

Fuente: elaboración propia. 


\section{Cuadro 4}

\section{ESPACIOS CULTURALES DE ORIGEN INDUSTRIAL ANALIZADOS}

\begin{tabular}{|c|c|c|}
\hline Elementos de patrimonio industrial & Espacio cultural & Uso cultural \\
\hline 1. Real Fábrica de Aguardientes y Naipes & CSA La Tabacalera de Lavapiés & $\begin{array}{l}\text { Centro de Cultura } \\
\text { Contemporánea }\end{array}$ \\
\hline 2. Real Fábrica de Aguardientes y Naipes & Tabacalera Promoción del Arte & Sala de Exposiciones \\
\hline 3. Real Fábrica de Tapices & Real Fábrica de Tapices & Museos \\
\hline $\begin{array}{l}\text { 4. Central elevadora y primer depósito del Canal } \\
\text { de lsabel II }\end{array}$ & Sala Canal Isabel II & Sala de Exposiciones \\
\hline 5. Estación de Delicias & Museo del Ferrocarril de Madrid & Museo \\
\hline 6. Estación de Atocha & $\begin{array}{l}\text { Jardín Tropical Estación de } \\
\text { Atocha } \\
\end{array}$ & Jardín \\
\hline 7. Mercado de San Miguel & Mercado de San Miguel & $\begin{array}{l}\text { Centro de Cultura } \\
\text { Contemporánea }\end{array}$ \\
\hline \multirow[t]{2}{*}{ 8. Fábrica de cervezas El Águila } & $\begin{array}{l}\text { Biblioteca Regional Joaquín } \\
\text { Leguina }\end{array}$ & Biblioteca y Archivo \\
\hline & Sala "El Águila" & Sala de Exposiciones \\
\hline 9. Antigua central eléctrica de Pacífico & Nave de Motores. Anden 0. & Museos \\
\hline 10. Central eléctrica del Mediodía & Caixa Fórum & $\begin{array}{l}\text { Centro de Cultura } \\
\text { Contemporánea }\end{array}$ \\
\hline 11. Serrería de los Belgas & Medialab-Prado & $\begin{array}{l}\text { Centro de Cultura } \\
\text { Contemporánea }\end{array}$ \\
\hline 12. Fábrica Vda. e Hijos de Casimiro Mahou & $\begin{array}{l}\text { Museo ABC del Dibujo y la } \\
\text { Ilustración }\end{array}$ & Museo \\
\hline 13. Instalaciones del Canal Isabel II & Fundación Canal & Sala de Exposiciones \\
\hline 14. Fábrica de galletas Pacisa & Teatro Circo Price & Teatro \\
\hline 15. Matadero municipal y Mercado de ganados & Matadero Madrid & $\begin{array}{l}\text { Centro de Cultura } \\
\text { Contemporánea }\end{array}$ \\
\hline 16. Talleres de Atocha (Renfe) & La Neomudéjar & $\begin{array}{l}\text { Centro de Cultura } \\
\text { Contemporánea }\end{array}$ \\
\hline 17. Estación de Metro Chamberí & Andén 0. Estación de Chamberí & Museo \\
\hline 18. Taller de vehículos y garaje & Sala de Teatro Cuarta Pared & Teatro \\
\hline
\end{tabular}

Fuente. Elaboración propia.

\subsection{La caracterización de los espacios culturales de origen industrial del municipio de Madrid en función de sus nuevos usos}

La caracterización de los espacios culturales de origen industrial (Figura 2) revela que el 31,6\% han sido transformados en "Centros de Cultura Contemporánea". Por su parte, el 26,3\% de los elementos de patrimonio industrial se ha transformado en "Museos". En este caso, a excepción de la "Fábrica Vda. e Hijos de Casimiro Mahou", que en el 2010 abrió sus puertas como "Museo ABC del Dibujo y la Ilustración”, el resto de bienes han habilitado colecciones vinculadas con su actividad industrial original. El caso contrario se corresponde con el uso "Salas de Exposiciones" que alcanza el 21,1\% de los casos analizados. La arquitectura del edifico es la única reminiscencia de la actividad industrial 
original puesto que las temáticas de las exposiciones son ajenas a la industrialización. Por otro lado, el 10,5\% de los bienes industriales inventariados se han transformado en "Teatros". Sin embargo, los dos casos detectados podrían considerarse salas de artes escénicas alternativas. Recordemos que el "Teatro Price" es un circo móvil y la "Sala Cuarta Pared" surge como un "núcleo plural y dinamizador de las artes escénicas contemporáneas"3. Finalmente, el 5,3\% de los espacios culturales han sido transformados en "Jardines" y en "Archivos y Bibliotecas".

\section{Figura 2}

\section{USOS DE LOS ESPACIOS CULTURALES DE ORIGEN INDUSTRIAL}

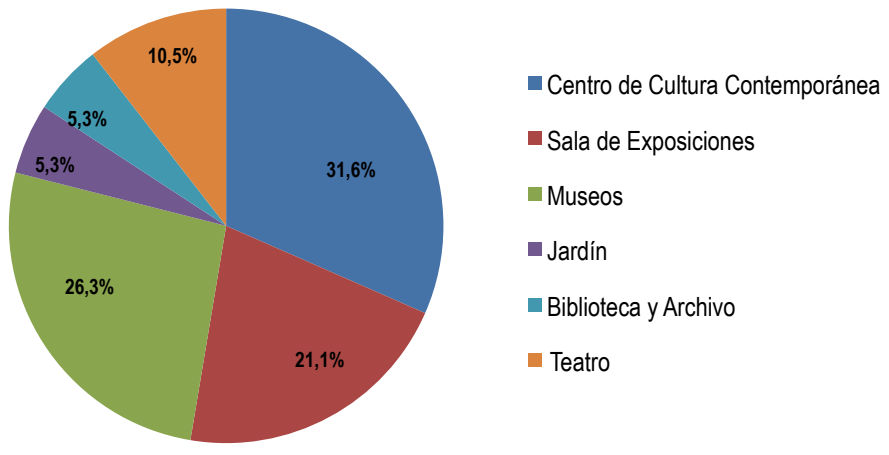

Fuente: elaboración propia.

\subsection{La aplicación de indicadores para evaluar la operatividad turística de los espa- cios culturales de origen industrial}

Tal y como se ha comentado, con el objetivo de evaluar la operatividad turística de los espacios culturales de origen industrial se han diseñado 20 indicadores (Cuadro 3). Este grupo de indicadores han sido implementados en dos matrices complementarias con el fin de alcanzar no solo un mayor número de datos sino también para enriquecer la información obtenida y obtener un grado más alto de validación. En primer lugar, se ha elaborado una matriz donde los indicadores han sido formulados mediante la escala Likert, con los siguientes ítems: si, valor 1; no, valor 0 . La segunda matriz ha sido elaborada también utilizando una escala Likert con los siguientes ítems: alto, valor 3; medio, valor 2; bajo, valor 1; nulo, valor 0 . En la primera matriz, la puntuación que puede alcanzar un espacio cultural oscila entre una horquilla de 0 a 4 por bloque de indicadores y de 0 a 20 en total. En la segunda matriz (Cuadro 5), la horquilla es de 0 a 12, en el primer caso y de 0 a 60 , en el segundo caso. En la presente investigación, por limitaciones de espacio, se presenta tan solo la segunda matriz por considerarse la más valiosa para el estudio.

3 http://www.cuartapared.es/index.php/inicio/quienes-somos/249-quienes-somos.html. 


\section{Cuadro 5}

\section{MATRIZ DE OPERATIVIDAD TURÍSTICA}

\begin{tabular}{|c|c|c|c|c|c|c|c|c|c|c|c|c|c|c|c|c|c|c|c|c|}
\hline & & I17 & I1 & I2 & I3 & I7 & I8 & I9 & I18 & $\mathrm{I13}$ & I4 & 16 & $\mathrm{I12}$ & I14 & $\mathrm{I} 15$ & I16 & $\mathrm{I10}$ & 15 & I11 & Total \\
\hline \multirow{4}{*}{$\begin{array}{l}\text { Paisaje } \\
\text { Urbano }\end{array}$} & ID13 & 3 & 2 & 3 & 3 & 3 & 3 & 3 & 3 & 3 & 3 & 3 & 3 & 2 & 3 & 3 & 2 & 3 & 3 & 51 \\
\hline & ID14 & 1 & 2 & 2 & 2 & 2 & 3 & 3 & 2 & 3 & 3 & 3 & 3 & 3 & 3 & 2 & 3 & 3 & 3 & 46 \\
\hline & ID15 & 1 & 2 & 2 & 2 & 2 & 1 & 1 & 2 & 1 & 2 & 1 & 1 & 3 & 1 & 3 & 3 & 3 & 3 & 34 \\
\hline & ID16 & 1 & 1 & 1 & 1 & 1 & 1 & 1 & 1 & 2 & 2 & 3 & 3 & 2 & 3 & 2 & 3 & 3 & 3 & 34 \\
\hline \multirow{2}{*}{\multicolumn{2}{|c|}{\begin{tabular}{|l|} 
Total \\
\end{tabular}}} & 6 & 7 & 8 & 8 & 8 & 8 & 8 & 8 & 9 & 10 & 10 & 10 & 10 & 10 & 10 & 11 & 12 & 12 & 165 \\
\hline & & I6 & I12 & I3 & I8 & I9 & I18 & I1 & I2 & I4 & 15 & I10 & I11 & I17 & 17 & I13 & I14 & I15 & I16 & Total \\
\hline \multirow{4}{*}{ Accesibilidad } & ID1 & 2 & 2 & 3 & 3 & 3 & 3 & 2 & 2 & 2 & 2 & 2 & 2 & 3 & 3 & 3 & 3 & 3 & 3 & 46 \\
\hline & ID2 & 2 & 2 & 2 & 2 & 2 & 2 & 3 & 3 & 3 & 3 & 3 & 3 & 3 & 3 & 3 & 3 & 3 & 3 & 48 \\
\hline & ID3 & 0 & 0 & 0 & 0 & 0 & 0 & 0 & 0 & 0 & 0 & 0 & 0 & 0 & 0 & 0 & 0 & 0 & 0 & 0 \\
\hline & ID4 & 2 & 2 & 2 & 2 & 2 & 2 & 3 & 3 & 3 & 3 & 3 & 3 & 2 & 3 & 3 & 3 & 3 & 3 & 47 \\
\hline \multicolumn{2}{|l|}{ Total } & 6 & 6 & 7 & 7 & 7 & 7 & 8 & 8 & 8 & 8 & 8 & 8 & 8 & 9 & 9 & 9 & 9 & 9 & 141 \\
\hline & & I5 & I8 & I9 & I17 & 17 & $\mathrm{I3}$ & I1 & I2 & I4 & I6 & I11 & I12 & I14 & $\mathrm{I} 15$ & $\mathrm{I} 16$ & I10 & I13 & I18 & Total \\
\hline \multirow{4}{*}{$\begin{array}{l}\text { Información } \\
\text { web }\end{array}$} & ID9 & 0 & 0 & 0 & 0 & 0 & 3 & 3 & 3 & 3 & 3 & 3 & 3 & 3 & 3 & 3 & 3 & 3 & 3 & 39 \\
\hline & ID10 & 0 & 2 & 2 & 2 & 2 & 2 & 3 & 3 & 3 & 3 & 3 & 3 & 3 & 3 & 3 & 3 & 3 & 3 & 46 \\
\hline & ID11 & 0 & 1 & 1 & 1 & 2 & 1 & 2 & 3 & 3 & 3 & 3 & 3 & 3 & 3 & 3 & 3 & 3 & 3 & 41 \\
\hline & ID12 & 0 & 0 & 0 & 0 & 0 & 0 & 0 & 0 & 0 & 0 & 0 & 0 & 0 & 0 & 0 & 2 & 2 & 2 & 6 \\
\hline \multicolumn{2}{|l|}{ Total } & 0 & 3 & 3 & 3 & 4 & 6 & 8 & 9 & 9 & 9 & 9 & 9 & 9 & 9 & 9 & 11 & 11 & 11 & 132 \\
\hline & & I18 & I1 & I8 & I9 & I13 & I15 & I17 & I7 & I16 & 12 & I3 & I4 & I5 & I12 & I14 & I6 & I10 & I11 & Total \\
\hline \multirow{4}{*}{$\begin{array}{l}\text { Potencial } \\
\text { turístico }\end{array}$} & ID17 & 1 & 2 & 1 & 1 & 1 & 1 & 1 & 1 & 2 & 2 & 2 & 2 & 3 & 3 & 3 & 3 & 3 & 3 & 35 \\
\hline & \begin{tabular}{|l|} 
ID18 \\
\end{tabular} & 2 & 2 & 2 & 2 & 1 & 1 & 2 & 2 & 2 & 2 & 3 & 2 & 3 & 2 & 2 & 3 & 3 & 3 & 39 \\
\hline & ID19 & 0 & 0 & 1 & 1 & 2 & 2 & 1 & 2 & 1 & 2 & 2 & 0 & 1 & 2 & 2 & 2 & 2 & 2 & 25 \\
\hline & \begin{tabular}{|l} 
ID20 \\
\end{tabular} & 0 & 0 & 0 & 0 & 0 & 0 & 0 & 0 & 0 & 0 & 0 & 3 & 0 & 0 & 0 & 0 & 0 & 0 & 3 \\
\hline \multirow{2}{*}{\multicolumn{2}{|c|}{ Total }} & 3 & 4 & 4 & 4 & 4 & 4 & 4 & 5 & 5 & 6 & 7 & 7 & 7 & 7 & 7 & 8 & 8 & 8 & 102 \\
\hline & & I17 & I16 & I18 & I12 & I13 & I14 & I10 & I11 & I15 & 14 & I5 & I6 & I8 & I3 & 17 & I9 & I1 & I2 & Total \\
\hline \multirow{4}{*}{$\begin{array}{c}\text { Afecciones } \\
\text { legales }\end{array}$} & ID5 & 0 & 1 & 0 & 1 & 1 & 1 & 1 & 2 & 2 & 3 & 3 & 3 & 3 & 3 & 3 & 3 & 3 & 3 & 36 \\
\hline & ID6 & 0 & 0 & 0 & 0 & 0 & 0 & 0 & 0 & 0 & 3 & 3 & 3 & 3 & 3 & 3 & 3 & 3 & 3 & 27 \\
\hline & ID7 & 0 & 0 & 0 & 0 & 0 & 0 & 0 & 0 & 0 & 0 & 0 & 0 & 0 & 0 & 0 & 0 & 0 & 0 & 0 \\
\hline & ID8 & 0 & 0 & 1 & 1 & 1 & 2 & 3 & 2 & 3 & 0 & 0 & 0 & 0 & 2 & 2 & 2 & 3 & 3 & 25 \\
\hline \multicolumn{2}{|l|}{\begin{tabular}{|l} 
Total \\
\end{tabular}} & 0 & 1 & 1 & 2 & 2 & 3 & 4 & 4 & 5 & 6 & 6 & 6 & 6 & 8 & 8 & 8 & 9 & 9 & 88 \\
\hline
\end{tabular}

Leyenda de las abreviaturas referidas a los espacios culturales

\begin{tabular}{|l|c|l|l|}
\hline CSA La Tabacalera de Lavapiés & I1 & Caixa Fórum & I10 \\
\hline Tabacalera Promoción del Arte & I2 & Medialab-Prado & I11 \\
\hline Real Fábrica de Tapices & I3 & Museo ABC del Dibujo y la Ilustración & I12 \\
\hline Museo del Ferrocarril de Madrid & I4 & Fundación Canal & I13 \\
\hline Jardín Tropical Estación de Atocha & I5 & Circo Price & I14 \\
\hline Mercado de San Miguel & I6 & Matadero Madrid & I15 \\
\hline Biblioteca Regional Joaquín Leguina & I7 & La Neomudéjar & I16 \\
\hline Nave de Motores. Anden 0 & I8 & Andén 0. Estación de Chamberí & I17 \\
\hline Sala Canal Isabel II & I9 & Sala de teatro Cuarta Pared & I18 \\
\hline
\end{tabular}

\section{Leyenda de las abreviaturas referidas a los indicadores}

\begin{tabular}{|l|c|l|l|}
\hline Acceso al tráfico rodado & ID1 & Información web avanzada & ID11 \\
\hline Cercanía al transporte público & ID2 & Posibilidad de e-commerce & ID12 \\
\hline Aparcamiento gratuito próximo & ID3 & Rehabilitación de las edificaciones integradas en el espacio & ID13 \\
\hline Cercanía a nudos de transporte & ID4 & Mejora del espacio urbano próximo & ID14 \\
\hline Grado de protección municipal & ID5 & Proximidad a otros espacios culturales de origen industrial & ID15 \\
\hline Grado de protección estatal & ID6 & Grado de integración del espacio cultural en el ámbito urbano & ID16 \\
\hline Integración del espacio cultural en planes turísticos & ID7 & Proximidad del espacio cultural a los principales atractivos turísticos & ID17 \\
\hline Integración del espacio cultural en planes culturales & ID8 & Proximidad de oferta complementaria turística de calidad & ID18 \\
\hline Información web & ID9 & Grado de promoción a través de organismos públicos & ID19 \\
\hline Información web básica & ID10 & Comercialización del espacio cultural a través de organismos pub/pri & ID20 \\
\hline
\end{tabular}




\section{PRINCIPALES RESULTADOS DE LA INVESTIGACIÓN}

Una vez aplicados los indicadores, los resultados obtenidos han sido estructurados en dos grupos, por un lado, se ha realizado una jerarquización de los 5 indicadores en función de las puntuaciones obtenidas, desde un punto de vista desagregado y agregado (Cuadros 6 y 7). Serán presentados de mayor a menor puntuación; y, por otro, se han categorizado los espacios culturales de origen industrial en función de su grado de operatividad turística.

\subsection{Jerarquización de los indicadores en función de las puntuaciones obtenidas}

\subsubsection{Paisaje urbano. La excelente conservación de la arquitectura industrial y su inte- gración en los espacios urbanos}

El análisis estadístico revela que el paisaje urbano es el indicador en el que los espacios culturales de origen industrial han obtenido una mayor puntuación, un total de 165 sobre 216 posibles (Cuadro 5). El 11\% de los espacios culturales analizados alcanzan valores medios en este indicador, entre 31 y 45 puntos; el $2 \%$ valores bajos, entre 16 y 30 puntos; y, finalmente, el $5 \%$ puntúa nulo, entre 0 y 15 (Cuadro 7). El análisis desagregado del indicador "paisaje urbano" revela que el $83 \%$ de los espacios culturales alcanzan valores altos en el ítem "rehabilitación de los edificios integrados en los espacios culturales" y el $62 \%$ en el indicador "mejora del espacio urbano" (Cuadro 6).

Estos datos confirman la realidad actual de los espacios culturales de origen industrial. Todos los bienes se encuentran en un estado de conservación idóneo puesto que han sido sometidos a proyectos de rehabilitación integral para adaptarse a nuevos usos. Consecuentemente, esta transformación ha favorecido la mejora del espacio urbano próximo resultando el caso del "Caixa Fórum" un ejemplo paradigmático al respecto. No obstante, es conveniente realizar una serie de matizaciones respecto al indicador "paisaje urbano". Mientras que hay espacios culturales como el "Matadero Madrid" o el "Caixa Fórum" que se han abierto a la ciudad a través de plazas diáfanas, la gran mayoría se cierran al tejido urbano perdiéndose la posibilidad de integrar estos elementos de gran valor arquitectónico en la ciudad como espacios públicos abiertos (Tabacalera de Lavapiés, Sala de Exposiciones Canal de Isabel II, Real Fábrica de Tapices, etc.). De ahí que los resultados estadísticos resulten dispersos en el indicador "grado de integración del espacio cultural en el ámbito urbano". El 34\% de los espacios culturales alcanzan valores altos, el $22 \%$ valores medios y el $44 \%$, valores bajos (Cuadro 6).

Por otro lado, existen un conjunto de espacios que se encuentran próximos entre sí (Caixa Forum, Medialab-Prado, Neomudéjar, Circo Price y Tabacalera de Lavapiés) mientras que otros se encuentran alejados y, además, aislados (Museo del ABC del Dibujo y la Ilustración, Fundación Canal de Isabel II, etc.). Si bien es verdad que no se ha detectado hasta la actualidad ningún tipo de promoción o comercialización conjunta de tipo cultural o turístico, en caso de que ésta se produjera, la ubicación de los elementos sería un factor a tener en cuenta. Al igual que en el caso anterior, esta polarización se refleja en una dispersión de los datos estadísticos referidos al ítem "proximidad a otros espacios culturales de origen industrial". El 28\% de los espacios culturales alcanzan valores altos; el 33\%, valores medios; y, el 39\%, valores bajos (Cuadro 6). 


\section{Cuadro 6}

\section{RESULTADOS DE LA APLICACIÓN POR GRUPOS DE INDICADORES}

\begin{tabular}{|c|c|c|c|c|c|}
\hline & & ALTO & MEDIO & BAJO & NULO \\
\hline \multirow{4}{*}{ Accesibilidad } & Acceso al tráfico rodado & $56 \%$ & $44 \%$ & $0 \%$ & $0 \%$ \\
\hline & Cercanía al transporte público & $67 \%$ & $33 \%$ & $0 \%$ & $0 \%$ \\
\hline & Aparcamiento gratuito próximo & $0 \%$ & $0 \%$ & $0 \%$ & $100 \%$ \\
\hline & Cercanía a nudos de transporte & $61 \%$ & $39 \%$ & $0 \%$ & $0 \%$ \\
\hline \multirow{4}{*}{$\begin{array}{l}\text { Afecciones } \\
\text { legales }\end{array}$} & Grado de protección municipal & $50 \%$ & $11 \%$ & $28 \%$ & $11 \%$ \\
\hline & Grado de protección estatal & $50 \%$ & $0 \%$ & $0 \%$ & $50 \%$ \\
\hline & Integración del espacio cultural en planes turísticos & $0, \%$ & $0 \%$ & $0 \%$ & $100 \%$ \\
\hline & Integración del espacio cultural en planes culturales & $22 \%$ & $28 \%$ & $17 \%$ & $33 \%$ \\
\hline \multirow{4}{*}{$\begin{array}{l}\text { Información } \\
\text { web }\end{array}$} & Información web & $72 \%$ & $0 \%$ & $0 \%$ & $28 \%$ \\
\hline & Información web básica & $67 \%$ & $28 \%$ & $0 \%$ & $5 \%$ \\
\hline & Información web avanzada & $61 \%$ & $11 \%$ & $22 \%$ & $6 \%$ \\
\hline & Posibilidad de e-commerce & $0 \%$ & $17 \%$ & $0 \%$ & $83 \%$ \\
\hline \multirow{4}{*}{$\begin{array}{l}\text { Paisaje } \\
\text { urbano }\end{array}$} & $\begin{array}{l}\text { Rehabilitación de las edificaciones integradas en el } \\
\text { espacio cultural }\end{array}$ & $83 \%$ & $17 \%$ & $0 \%$ & $0 \%$ \\
\hline & Mejora del espacio urbano próximo & $62 \%$ & $33 \%$ & $5 \%$ & $0 \%$ \\
\hline & $\begin{array}{l}\text { Proximidad a otros espacios culturales de origen } \\
\text { industrial }\end{array}$ & $28 \%$ & $33 \%$ & $39 \%$ & $0 \%$ \\
\hline & $\begin{array}{l}\text { Grado de integración del espacio cultural en el } \\
\text { ámbito urbano }\end{array}$ & $34 \%$ & $22 \%$ & $44 \%$ & $0 \%$ \\
\hline \multirow{4}{*}{$\begin{array}{l}\text { Potencial } \\
\text { turístico }\end{array}$} & $\begin{array}{l}\text { Proximidad del espacio cultural a los principales } \\
\text { atractivos turísticos de la ciudad }\end{array}$ & $33 \%$ & $28 \%$ & $39 \%$ & $0 \%$ \\
\hline & $\begin{array}{l}\text { Proximidad de oferta complementaria turística de } \\
\text { calidad }\end{array}$ & $28 \%$ & $61 \%$ & $11 \%$ & $0 \%$ \\
\hline & Grado de promoción a través de organismos públicos & $0 \%$ & $55 \%$ & $28 \%$ & $17 \%$ \\
\hline & $\begin{array}{l}\text { Comercialización del espacio cultural a través de } \\
\text { organismos públicos y/o privados }\end{array}$ & $5 \%$ & $0 \%$ & $0 \%$ & $95 \%$ \\
\hline
\end{tabular}

Fuente: elaboración propia.

\subsubsection{Accesibilidad. La ubicación estratégica de los espacios culturales de origen industrial}

El segundo indicador en el que más han puntuado los espacios culturales de origen industrial es "accesibilidad", obteniendo una puntuación de 141 (Cuadro 5). El 72,2\% de los ítems alcanzan en este indicador una puntuación baja y el 27,8\% una puntuación media. No hay valores nulos ni altos (Cuadro 7). Por otro lado, el análisis estadístico desagregado manifiesta valores medios y altos en los indicadores "acceso al tráfico rodado", "cercanía al transporte público" y "cercanía a nudos de transporte". Todos los bienes tienen una excelente accesibilidad al tráfico rodado, se encuentran próximos al transporte público e, incluso a nudos de transportes (Cuadro 6). De hecho, los espacios mencionados anteriormente por su cercanía entre sí (Caixa Fórum, Medialab-Prado, Neomudéjar, Circo Price y Tabacalera de Lavapiés), se ubican estratégicamente en las proximidades de la Estación de Atocha, uno de los nudos de comunicación más relevantes de nuestro país. El único aspecto disuasorio de la operatividad turística en lo que a la accesibilidad se refiere es la ausencia de aparcamientos 
gratuitos en las proximidades de los espacios culturales, si bien es verdad que al posicionarse tan aisladamente en este indicador, no debería obstaculizar por sí mismo la operatividad turística. Consecuentemente, en el indicador "aparcamiento gratuito próximo" el valor que se alcanza en el 100\% de los casos analizados es "nulo" (Cuadro 6).

\section{Cuadro 7}

\section{PUNTUACIONES OBTENIDAS EN EL CONJUNTO DE INDICADORES}

\begin{tabular}{|l|c|c|c|}
\hline \multicolumn{4}{|c|}{ PAISAJE URBANO } \\
\hline Categoría & Grupos & Total & Total (\%) \\
\hline Nulo & $0-15$ & 5 & $0 \%$ \\
\hline Bajo & $16-30$ & 2 & $44,4 \%$ \\
\hline Medio & $31-45$ & 11 & $55,6 \%$ \\
\hline Alto & $46-60$ & 0 & $0 \%$ \\
\hline Total & $\mathbf{1 8}$ & $\mathbf{1 0 0 \%}$ \\
\hline
\end{tabular}

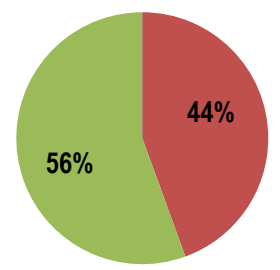

Nulo

\begin{tabular}{|l|c|c|c|}
\hline \multicolumn{4}{|c|}{ ACCESIBILIDAD } \\
\hline Categoría & Grupos & Total & Total (\%) \\
\hline Nulo & $0-15$ & 0 & $0 \%$ \\
\hline Bajo & $16-30$ & 13 & $72,2 \%$ \\
\hline Medio & $31-45$ & 5 & $27,8 \%$ \\
\hline Alto & $46-60$ & 0 & $0 \%$ \\
\hline Total & $\mathbf{1 8}$ & $\mathbf{1 0 0 \%}$ \\
\hline
\end{tabular}

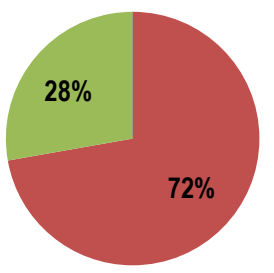

Nulo

Bajo

Medio

Alto

\begin{tabular}{|l|c|c|c|}
\hline \multicolumn{4}{|c|}{ INFORMACIÓN WEB } \\
\hline Categoría & Grupos & Total & Total (\%) \\
\hline Nulo & $0-15$ & 5 & $27,8 \%$ \\
\hline Bajo & $16-30$ & 2 & $11,1 \%$ \\
\hline Medio & $31-45$ & 11 & $61,1 \%$ \\
\hline Alto & $46-60$ & 0 & $0 \%$ \\
\hline Total & $\mathbf{1 8}$ & $\mathbf{1 0 0 \%}$ \\
\hline
\end{tabular}

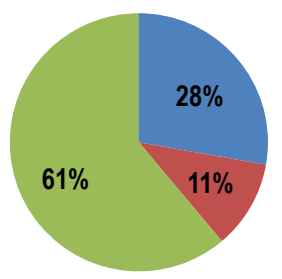

Nulo

Bajo

Medio

Alto

\begin{tabular}{|l|c|c|c|}
\hline \multicolumn{4}{|c|}{ POTENCIAL TURÍSTICO } \\
\hline Categoría & Grupos & Total & Total (\%) \\
\hline Nulo & $0-15$ & 5 & $44,4 \%$ \\
\hline Bajo & $16-30$ & 2 & $55,6 \%$ \\
\hline Medio & $31-45$ & 11 & $0 \%$ \\
\hline Alto & $46-60$ & 0 & $0 \%$ \\
\hline Total & $\mathbf{1 8}$ & $\mathbf{1 0 0 \%}$ \\
\hline
\end{tabular}

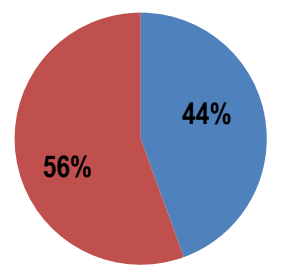

Nulo

\begin{tabular}{|l|c|c|c|}
\hline \multicolumn{4}{|c|}{ AFECCIONES LEGALES } \\
\hline Categoría & Grupos & Total & Total (\%) \\
\hline Nulo & $0-15$ & 8 & $44,4 \%$ \\
\hline Bajo & $16-30$ & 8 & $44,4 \%$ \\
\hline Medio & $31-45$ & 2 & $11,1 \%$ \\
\hline Alto & $46-60$ & 0 & $0 \%$ \\
\hline Total & $\mathbf{1 8}$ & $\mathbf{1 0 0 \%}$ \\
\hline
\end{tabular}

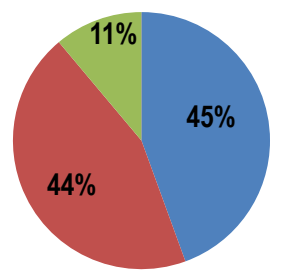

Nulo

Bajo

Medio

Alto

Fuente: elaboración propia. 


\subsubsection{Información web. La difusión de contenidos digitales}

Con 132 puntos, el indicador "información web" arroja resultados dispersos (Cuadro 5). El $61,1 \%$ de los espacios culturales analizados alcanzan valores medios, el 11,1\% valores medios y el 27,8\% valores nulos (Cuadro 7). Por su parte, los datos estadísticos desagregados ponen de manifiesto que el $72 \%$ de los espacios culturales (Cuadro 6) cuentan con páginas web cuyos contenidos digitales informan sobre las principales características del centro, ya sea a través de su propia web (Tabacalera Promoción del Arte, Real Fábrica de Tapices, Mercado de San Miguel, etc.), o a través de portales corporativos (Anden 0. Nave de Motores, el Jardín Tropical de la Estación de Atocha, etc.). Hay que tener en cuenta que un $67 \%$ de esta información es básica adoleciendo de una interactuación con el usuario en redes sociales como sucede en el caso del "Jardín Tropical de la Estación de Atocha". Resulta especialmente relevante como el 83\% de los espacios culturales no desarrollan e-commerce (Cuadro 6), tan solo lo posibilitan el "Caixa Forum", la "Sala Cuarta Pared" y la "Fundación Canal", posiblemente por tener una mayor tradición en la organización de eventos culturales, especialmente, exposiciones y obras de teatro.

\subsubsection{Potencial turístico. La proximidad a la oferta turística de la ciudad}

El indicador "potencial turístico", con 102 puntos (Cuadro 5), evidencia polarización entre valores nulos, que suponen el 44\% del total, y niveles bajos, el 55,6\% (Cuadro 7). No se localizan valores medios y altos. Desde un punto de vista desagregado, los datos muestran que la mayoría de los centros se localizan próximos a los principales atractivos turísticos de la ciudad y a una oferta complementaria turística de calidad. La puntuación baja se centra en dos ítems, en primer lugar, la promoción que realizan los organismos públicos de estos espacios que resulta en algunos casos inexistente (Tabacalera de Lavapiés, Museo del Ferrocarril de Madrid y Sala de teatro Cuarta Pared), de hecho, los datos estadísticos arrojan resultados que oscilan entre valores medios (55\%), valores bajos (28\%) y valores nulos (17\%); y, en segundo lugar, en su comercialización a través de organismos públicos y/o privados que, al igual que en la situación anterior, es prácticamente nula. Solo hay un espacio cultural, el "Museo del Ferrocarril de Madrid", que alcanza un valor alto en el indicador "comercialización del espacio cultural a través de organismos públicos y/o privados" (Cuadro 6).

\subsubsection{Afecciones legales. La protección del patrimonio industrial como base de su trans-} formación en recursos culturales

El indicador "afecciones legales" es el que ha obtenido una menor puntuación, 88 puntos (Cuadro 5). El 44,4\% han obtenido valores nulos y bajos mientras que el $11,1 \%$ han conseguido puntaciones medias (Cuadro 7). En este caso, tampoco se han detectado puntuaciones altas. Este indicador ofrece resultados bastante dispersos desde un punto de vista desagregado, dado que básicamente todos los espacios culturales de origen industrial cuentan con protección municipal y/o estatal. De hecho, los datos estadísticos para los ítems "grado de protección municipal" e "integración del espacio en planes culturales" 
se distribuyen entre valores altos, medios, bajos y nulos. El "grado de protección estatal" se encuentra polarizado, el $50 \%$ de los espacios culturales ostenta protección BIC y el $50 \%$ no posee esta afección legal. Sin embargo, la integración de estos espacios en la planificación cultural y turística de la ciudad es su punto débil (Cuadro 6). Mientras que el PECAM contemplaba alguno de estos bienes, no por su valor industrial, sino por su funcionalidad como contenedor cultural y su práctica innovadora en la gestión cultural, su integración en la planificación turística de la ciudad es inexistente.

\subsection{Jerarquización de los espacios culturales de origen industrial en función de su operatividad turística}

Un análisis no desagregado de los indicadores aplicados sobre los espacios culturales de origen industrial (Cuadro 8) revela que el 22,2\% de los espacios culturales desarrollan una operatividad turística baja ${ }^{4}$. El 77,8\%, 14 ítems, desarrollan una operatividad media 5 . Ningún espacio cultural ha sido clasificado como nulo o bajo. Ante la imposibilidad de analizar las particularidades de cada uno de los casos seleccionados, puesto que los resultados serían demasiados extensos para este artículo, se ha considerado más oportuno profundizar en cuatro espacios culturales de origen industrial (Cuadro 9). Por un lado, en el "Caixa Fórum Madrid" puesto que se corresponde con el espacio cultural que ha obtenido una mayor puntuación en la matriz de operatividad turística, un total de 42 puntos. Por otro, en el caso opuesto, “Andén 0. Estación de Chamberî", el elemento que ha alcanzado un valor menor (21 puntos). Para complementar ambos ejemplos, también se han analizado los elementos "CSA. La Tabacalera de Lavapiés" y la "Real Fábrica de Tapices" por posicionarse en un término medio en las puntuaciones de la escala Likert, ambos con 36 puntos.

\section{Cuadro 8 \\ CATEGORIZACIÓN DE LOS ESPACIOS CULTURALES EN FUNCIÓN DE LA OPERATIVIDAD TURÍSTICA}

\begin{tabular}{|l|c|c|c|}
\hline Categoría & Grupos & Total & Total (\%) \\
\hline Nulo & $0-15$ & 0 & $0 \%$ \\
\hline Bajo & $16-30$ & 4 & $22,2 \%$ \\
\hline Medio & $31-45$ & 14 & $77,8 \%$ \\
\hline Alto & $66-60$ & 0 & $0 \%$ \\
\hline Total & $\mathbf{1 8}$ & $\mathbf{1 0 0}$ \\
\hline
\end{tabular}

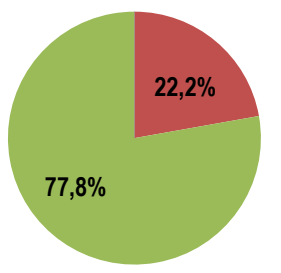

Nulo

- Bajo

Medio

Fuente: elaboración propia.

4 Andén 0. Estación de Chamberí, Nave de Motores. Andén 0 y Sala Canal de Isabel II.

5 Sala de teatro Cuarta Pared, Jardín Tropical Estación de Atocha, Biblioteca Regional Joaquín Leguina, Museo ABC del Dibujo y la Ilustración, la Neomudéjar, Fundación Canal, CSA. Tabacalera de Lavapiés, Real Fábrica de Tapices, Matadero de Madrid, Circo Price, Mercado de San Miguel, Tabacalera Promoción Arte, Museo del Ferrocarril, Medialab-Prado y Caixa Fórum Madrid. 


\section{Cuadro 9}

\section{PUNTUACIONES OBTENIDAS POR LOS ESPACIOS CULTURALES DE ORIGEN INDUSTRIAL}

\begin{tabular}{|c|c|c|c|c|c|c|c|c|c|c|c|c|c|c|c|c|c|c|c|}
\hline & 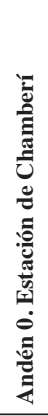 & 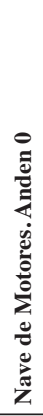 & 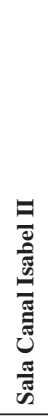 & 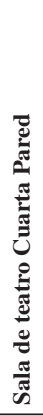 & 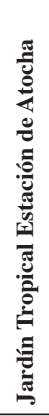 & 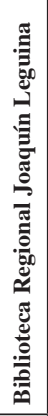 & 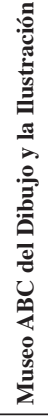 & 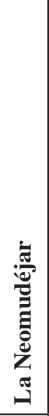 & 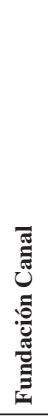 & 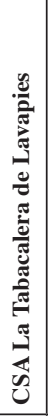 & 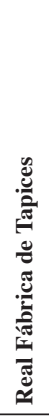 & 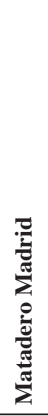 & 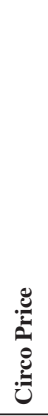 & 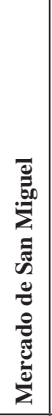 & 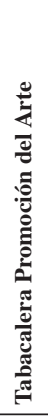 & 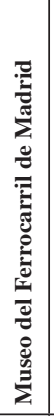 & 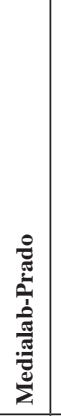 & 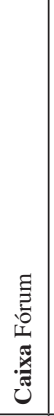 & 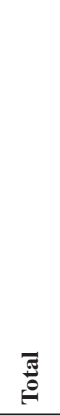 \\
\hline Accesibilidad & 8 & 7 & 7 & 7 & 8 & 9 & 6 & 9 & 9 & 8 & 7 & 9 & 9 & 6 & 8 & 8 & 8 & 8 & 141 \\
\hline Afecciones legales & 0 & 6 & 8 & 1 & 6 & 8 & 2 & 1 & 2 & 9 & 8 & 5 & 3 & 6 & 9 & 6 & 4 & 4 & 88 \\
\hline Información web & 3 & 3 & 3 & 11 & 0 & 4 & 9 & 9 & 11 & 8 & 6 & 9 & 9 & 9 & 9 & 9 & 9 & 11 & 132 \\
\hline Paisaje urbano & 6 & 8 & 8 & 8 & 12 & 8 & 10 & 10 & 9 & 7 & 8 & 10 & 10 & 10 & 8 & 10 & 12 & 11 & 165 \\
\hline Potencial turístico & 4 & 4 & 4 & 3 & 7 & 5 & 7 & 5 & 4 & 4 & 7 & 4 & 7 & 8 & 6 & 7 & 8 & 8 & 102 \\
\hline Total puntuación & 21 & 28 & 30 & 30 & 33 & 34 & 34 & 34 & 35 & 36 & 36 & 37 & 38 & 39 & 40 & 40 & 41 & 42 & 496 \\
\hline Puntuación posible & 60 & 60 & 60 & 60 & 60 & 60 & 60 & 60 & 60 & 60 & 60 & 60 & 60 & 60 & 60 & 60 & 60 & 60 & 1.080 \\
\hline
\end{tabular}

Fuente: elaboración propia.

"Caixa Fórum Madrid" es el elemento que ha obtenido un mayor valor, un total de 42 puntos sobre 60 posibles (Cuadro 9). Ha alcanzado 11 puntos sobre un total de 12, en los indicadores "paisaje urbano" e "información web"; 8 puntos en "accesibilidad" y "potencial turístico"; y, finalmente, 4 en "afecciones legales" (Figura 3). Esta puntuación refleja la realidad de la antigua Central eléctrica del Mediodía. Rehabilitada en el 2002 por la firma de arquitectos Herzog \& De Meuron e inaugurada en el año 2008 como "Caixa Fórum Madrid", se integra dentro del Paseo del Arte de Madrid dedicándose fundamental a las exposiciones temporales. Su ubicación en las proximidades de la Estación de Atocha, al metro y a diferentes líneas de autobuses lo convierte en un recurso muy accesible. El proyecto de rehabilitación apenas ha respetado el edificio original. Tan solo se conserva una fachada de ladrillo elevada con ventanales ciegos a la que se ha incorporado un techo metálico. No obstante, se ha generado una plaza que esponja la trama urbana y facilita su integración con el entramado urbano. Un jardín colgante ubicado en una fachada de la plaza suaviza la rigidez del entorno (Figura 4). Actualmente, la antigua central se encuentra protegida por el PGOU bajo la categoría Nivel 3 (Parcial). "Caixa Fórum Madrid" posee un portal web que ofrece una información avanzada con acceso a redes sociales y al comercio "on-line". 
“Andén 0. Estación de Chamberí" es el espacio cultural que menos valor ha alcanzado, un total de 21 puntos (Cuadro 9). La "accesibilidad" es el indicador en el que más puntuación ha obtenido, un total de 8, seguido por "paisaje urbano", con 6 puntos, e "información web", con 3. La puntuación del indicador "afecciones legales" es 0 (Figura 3). La antigua estación de Chamberí, diseñada por Antonio Palacios, formaba parte de la primera línea de metro de Madrid que, inaugurada en 1919, conectaba ocho estaciones (Cuatro Caminos, Río Rosas, Martínez Campos, Chamberí, Glorieta de Bilbao, Hospicio, Red de San Luis y Puerta del Sol). Ubicada en pleno barrio de Chamberí, este espacio cultural se encuentra próximo a líneas de metro y autobús aunque aislado respecto a otros espacios culturales de origen industrial y relativamente alejado de los principales recursos turísticos de la ciudad. Su estado de conservación es muy bueno aunque no se integra en el paisaje urbano de la ciudad puesto que se encuentra, como una estación de metro antigua que es, en el subsuelo de la ciudad (Figura 5). No posee un portal web propio, pero se puede acceder a información básica sobre el espacio cultural en el portal corporativo de Metro Madrid.

\section{Figura 3 \\ JERARQUIZACIÓN DE LOS ESPACIOS CULTURALES EN FUNCIÓN DE LA PUNTUACIÓN DE LOS INDICADORES}

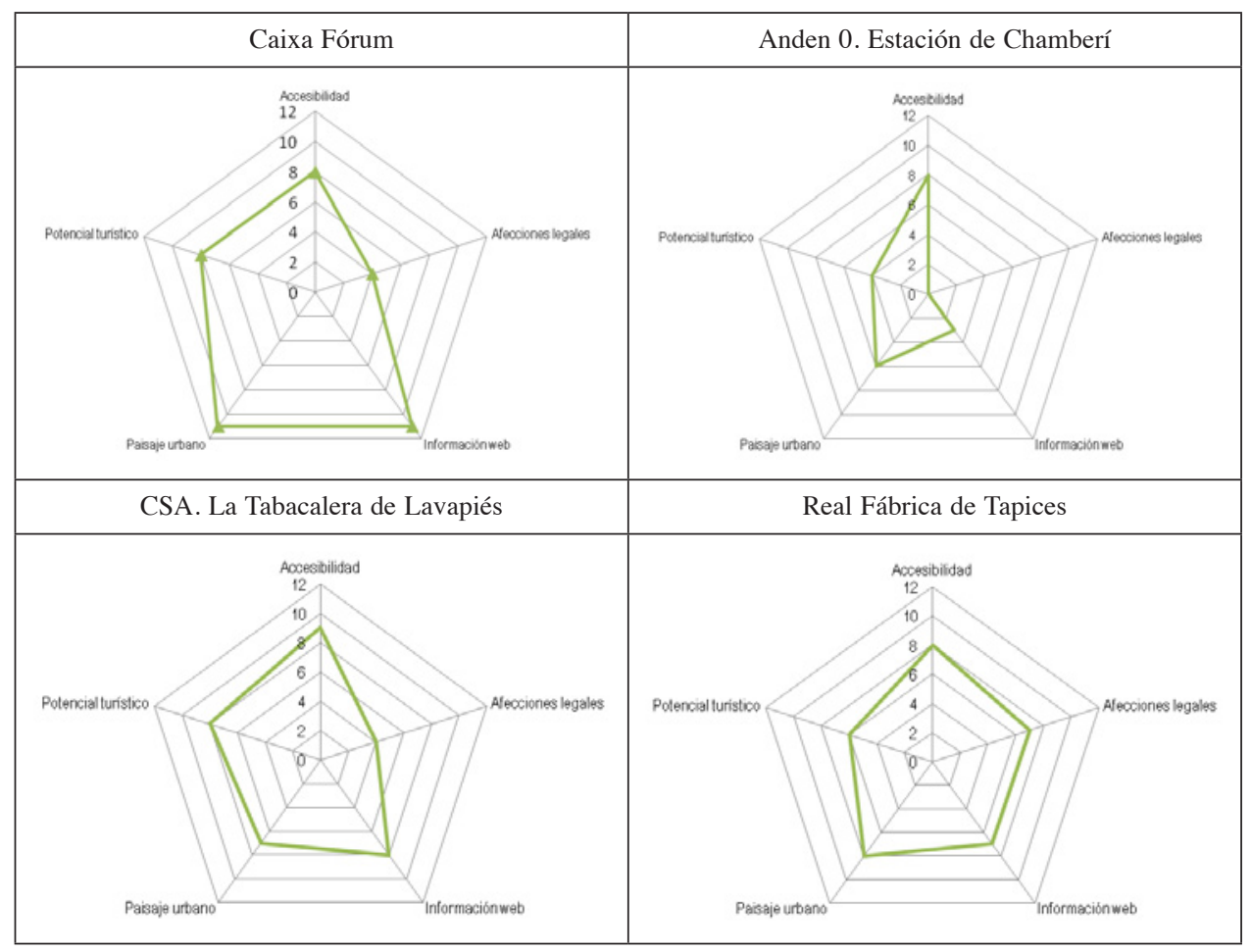

Fuente: elaboración propia. 


\section{Figura 4 \\ ESPACIO PÚBLICO GENERADO TRAS LA REHABILITACIÓN DE LA ANTIGUA ESTACIÓN ELÉCTRICA DEL MEDIODÍA}

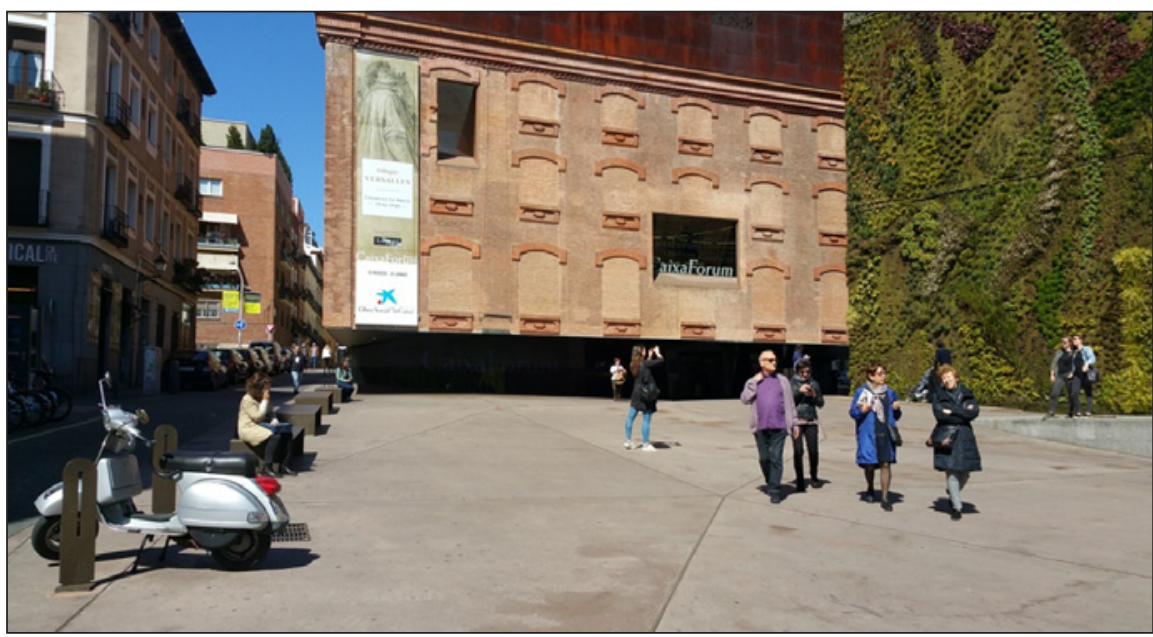

Fuente: Autores.

Figura 5

ANDEN 0. ESTACIÓN DE CHAMBERÍ

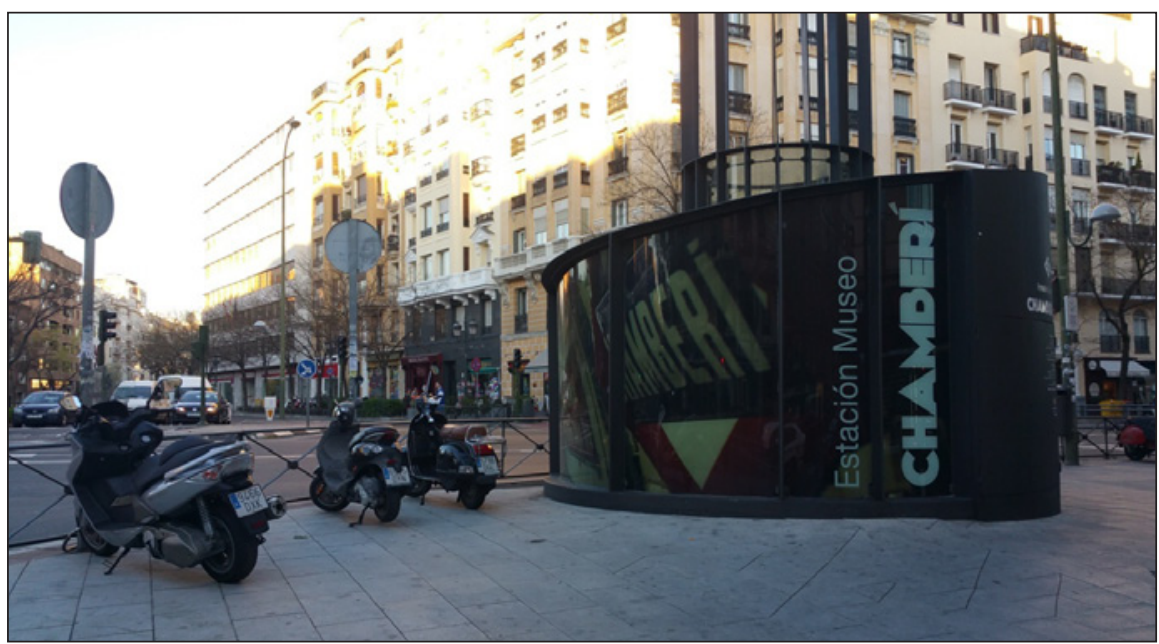

Fuente: Autores.

En un punto intermedio estarían "CSA. La Tabacalera de Lavapiés" y la "Real Fábrica de Tapices", ambas con 36 puntos (Cuadro 9). En el primer caso, el indicador "accesibilidad" es el ítem que más ha puntuado, un total de 9, seguido por los indi- 
cadores "información web" y "potencial turístico" con 8, "paisaje urbano" con 7; y, finalmente, "afecciones legales" con 4 (Figura 3). En el segundo caso, "Real Fábrica de Tapices", los indicadores "accesibilidad" y "paisaje urbano" puntúan 8 sobre 12, "afecciones legales" e "información web", un total de 7; y, finalmente, "potencial turístico", 6 (Figura 3). "CSA. La Tabacalera de Lavapiés”, la antigua Real Fábrica de Aguardientes y Naipes, se ubica en Embajadores. En sus proximidades se encuentran accesos a metro, autobús y tren. Tras el cese de su actividad en el año 2000 y la carencia de medios económicos para acometer su rehabilitación como Centro Nacional de Artes Visuales, se cedió su explotación al Centro Social Autogestionado "La Tabacalera". Tanto el proyecto del centro, de marcada orientación social, así como la agenda de las actividades pueden consultarse en su portal web. Se encuentra relativamente próximo a otros espacios culturales de origen industrial como el "Circo Price", la "Estación de Atocha", "MediaLab Prado" o "Caixa Fórum Madrid" así como de otros recursos turísticos de la ciudad, especialmente, del Paseo del Arte. Se encuentra rodeada de un murete por lo que su integración en el trazado urbano de la ciudad es prácticamente nulo. Ha sido declarado BIC bajo la categoría "Monumento" y ostenta el Nivel 1 de protección según el PGOU de Madrid.

Por su parte, la "Real Fábrica de Tapices", que sigue manteniendo su actividad productiva desde su fundación en 1720, se ubica en las proximidades de la Estación de Atocha. Tanto su accesibilidad como proximidad a otros recursos turísticos es muy elevada. Como en el caso anterior, ha sido declarado BIC bajo la categoría de "Monumento" y ostenta el Nivel 1 de protección según el PGOU de Madrid. A pesar de ello no se integra en la planificación turística o cultural de la ciudad. Como la "Tabacalera", tampoco se abre al trazado urbano de la ciudad. La información que ofrece en su página web se puede considerar básica.

\section{CONCLUSIONES PRINCIPALES Y PROPUESTAS}

Los datos obtenidos confirman la hipótesis apuntada al inicio de esta investigación. Los indicadores revelan una realidad muy precisa de la situación de los espacios culturales de origen industrial desde la perspectiva de la operatividad turística. Existen dos grupos de factores diferenciados, unos impulsan la transformación de estos recursos culturales en recursos turísticos y, por tanto, la posibilidad de crear productos susceptibles de ser comercializados que se integren en la oferta turística de la ciudad, mientras que otros frenan y obstaculizan la posibilidad de materializar este proceso. Entre los factores que contribuyen a la dinamización turística de estos espacios destacan por las altas puntuaciones obtenidas, cinco conjuntos de indicadores: la "rehabilitación de las edificaciones integradas en el espacio"; la "cercanía al transporte público"; el "acceso al tráfico rodado"; la "cercanía a nudos de transporte"; y, finalmente, la "información web básica".

De todos ellos, el primero, la "rehabilitación de las edificaciones integradas en el espacio" es el aspecto que más influye en la operatividad turística de los espacios industriales. Ello se debe a que el proyecto de rehabilitación para adaptar el edificio a nuevos usos culturales asegura la conservación del mismo y supone el punto de partida para 
convertirlo en recurso cultural y, posteriormente, en un recurso turístico. No obstante, es conveniente subrayar en este punto que algunas intervenciones, como la acometida en el "Caixa Fórum Madrid", han resultado excesivamente intervencionistas y apenas queda la fachada como vestigio de la arquitectura original. El segundo grupo de indicadores que destaca por su alta puntuación son los relacionados con la localización (cercanía al transporte público, acceso al tráfico rodado y cercanía a nudos de transporte). La mayoría de los espacios culturales se concentran en los distritos de Centro y Arganzuela, muy próximos a los principales recursos turísticos de la ciudad, una situación excepcional para atraer flujos turísticos y poner en marcha acciones de promoción y comercialización turística conjunta. Finalmente, el tercer indicador que alcanza una mayor puntuación es la "información web básica". Si la rehabilitación del edificio era el punto de partida para transformar los elementos de patrimonio industrial en recursos culturales y turísticos, la información lo es para promocionar estos espacios culturales y poner en marcha webs más dinámicas que ofrezcan más información e, incluso, integren herramientas de comercialización on-line.

Los resultados de la matriz también confirman la existencia de factores que, a diferencia de los citados anteriormente, reducen la operatividad turística de los espacios industriales. Entre los que han obtenido una puntuación más baja destacan "aparcamiento gratuito próximo", "integración del espacio cultural en planes turísticos", "comercialización del espacio cultural a través de organismos públicos y privados" y "posibilidad de e-commerce". La "integración del espacio cultural en planes turísticos" y la "comercialización del espacio cultural a través de organismos públicos y privados" son los que factores que más ahogan la operatividad turística de los espacios culturales de origen industrial puesto que manifiestan una ausencia muy grave de planificación turística y subrayan la inexistencia de una estrategia común para tratar de promocionar y comercializar este tipo de espacios. En el Plan Estratégico de Turismo 2012-2015 del Ayuntamiento de Madrid no se hacía referencia alguna a este tipo de patrimonio cultural, ni a su posible integración en modalidades de turismo cultural. Actualmente, el turismo no es una política prioritaria del consistorio municipal por lo que habrá que esperar a la redacción de un nuevo plan, esperemos, más sensible hacia este tipo de espacios culturales y a su potencialidad turística. En una situación similar se encuentra la planificación cultural, si ya se ha señalado anteriormente que el PECAM incluía alguno de estos espacios, incluso como referentes, el reciente cambio de equipo municipal deja en el aire este tema.

Otro de los aspectos que reduce considerablemente la operatividad turística de los espacios culturales es la baja promoción que los agentes públicos realizan de este tipo de elementos, tanto de una forma individual como colectiva. La información sobre estos espacios es escasa y en contadas ocasiones se incide en su carácter industrial. No se han detectado intentos por promocionar conjuntamente los espacios culturales bajo una posible temática de patrimonio industrial madrileño. Más acusado resulta el gravísimo problema de la comercialización. No solo no hay productos turísticos basados en estos espacios culturales sino que además su integración en la oferta turística de la ciudad resulta inexistente. 
A modo de diagnóstico general, se podría afirmar que no hay una estructura de turismo industrial en la ciudad a pesar de contar con recursos culturales de primer orden para ello. No hay herramientas que favorezcan la transformación de estos espacios industriales en recursos turísticos que incrementen y diversifiquen la oferta de turismo cultural existente en la ciudad. Además de esta debilidad, se ha detectado un claro desinterés o desconocimiento por parte de la administración pública municipal por integrar los espacios culturales de origen industrial en la oferta turística de la ciudad. Teniendo en cuenta estos aspectos, se proponen para finalizar este artículo una serie de propuestas prioritarias que llegadas a aplicarse podrían revertir esta situación:

- Propuesta 1. Sensibilizar a la administración municipal sobre la posibilidad de poner en marcha una modalidad de turismo urbano basado en los espacios culturales de origen industrial. El gobierno local es ajeno a cualquier tipo de iniciativa de esta naturaleza ya sea por desinterés o desconocimiento, y por ello resulta imprescindible que se sensibilice con este tipo de patrimonio industrial para, posteriormente, poder poner en marcha acciones de dinamización turística.

- Propuesta 2. Integrar los espacios industriales en la planificación turística y cultural municipal mediante acciones estratégicas que, por ejemplo, enlacen de forma coherente elementos industriales dispersos para así crear circuitos o rutas que expliquen la industrialización del territorio (Benito del Pozo, 2010). Desde el gobierno local, se deben diseñar planes estratégicos en cultura y turismo que integren propuestas relacionadas con la dinamización turística del patrimonio industrial en el corto, medio y largo plazo.

- Propuesta 3. Promoción público-privada de los espacios culturales de origen industrial de la ciudad. Es necesario incentivar la colaboración y cooperación entre los agentes involucrados en el desarrollo turístico y cultural de la ciudad para poder establecer actuaciones coordinadas que favorezcan el incremento de la oferta cultural y turística de la ciudad relacionada con el patrimonio industrial.

- Propuesta 4. Dar a conocer a los operadores turísticos de la ciudad la potencialidad turística de los espacios culturales de origen industrial. Resultaría interesante que, tanto la administración local como los especialistas en patrimonio industrial, dieran a conocer esta tipología de elementos culturales a los operadores turísticos con el fin de establecer sinergias de colaboración que deriven en el diseño de productos turísticos de calidad.

- Propuesta 5. Interpretar los espacios culturales dando a conocer su pasado industrial. Para favorecer que la sociedad conozca el origen industrial de este patrimonio cultural, sería conveniente que las estrategias de interpretación de estos antiguos espacios industriales integren aspectos relacionados con su funcionalidad pasada.

- Propuesta 6. Incorporar las TICs a los portales web de los espacios culturales de origen industrial favoreciendo la implantación de herramientas de comercio electrónico. La presencia on-line del patrimonio industrial como recurso turístico es prácticamente inexistente, así como su promoción, comercialización y perfiles sociales. Habría que incentivar, a través de herramientas de marketing digital y e-commerce su integración en las dinámicas 2.0 y 3.0. 


\section{BIBLIOGRAFÍA}

BARRADO, D. (2011): «Recursos territoriales y procesos geográficos: el ejemplo de los recursos turísticos», Estudios Geográficos, n 270, pp. 119-130.

BARRADO, D.; PALACIOS, A. e HIDALGO, C. (2013): «El turismo, una actividad esencial para la economía madrileña. Propuestas para la Revisión del Plan General de Ordenación Urbana de 1997», en Reflexiones a propósito de la Revisión del Plan General. Madrid, Grupo TRyS, pp. 317-336.

BLANCAS, F.; GONZÁLEZ, M.; GUERRERO, F. y LOZANO, M. (2010): «Indicadores sintéticos de turismo sostenible: una aplicación para los destinos turísticos de Andalucía», Rect@.Revista Electrónica de Comunicaciones y Trabajos de ASEPUMA, ${ }^{\circ}$ 11 , pp. 85-118.

BENITO DEL POZO, P. (2002): «Patrimonio industrial y cultural del territorio», Boletín de la Asociación de Geógrafos Españoles, n 34, pp. 213-227.

BENITO DEL POZO, P. (2010): «Territorio, herencia y paisaje industrial.: debates y acciones en el contexto europeo», Documents d'Anàlisi Geogràfica, vol. 58 (3), pp. 443-457.

BENITO DEL POZO, P. (2016): «Renovación urbana, herencia industrial y turismo: un proceso con elementos de éxito en Avilés (Asturias)», Boletín de la Asociación de Geógrafos Españoles, n $^{\circ}$ 72, pp. 285-304.

CAAMAÑO, I. (2011): «La comercialización del turismo industrial», ROTUR. Revista de Ocio y Turismo, no ${ }^{\circ}$, pp. 161-180.

CANDELA, P.; CASTILLO, J. y LÓPEZ, M. (2002): Arqueología industrial y memoria del trabajo: el patrimonio industrial del sudeste madrileño, 1905-1950. Aranjuez, Doce Calles.

CANDELA, P. (2006): «Diffusion and valorisation of the industrial archaeology of Comunidad de Madrid: one website experience», en XIII International Congress TICCIH. Terni, pp. 1-12.

CAÑIZARES, M.C. (1999): «Los símbolos mineros como elementos revitalizadores de la imagen urbana en la ciudad de Puertollano (Ciudad Real)», en El territorio y su imagen. Málaga, Asociación de Geógrafos Españoles y Universidad de Málaga, pp. 977-986.

CALLIZO, J. y LACOSTA, A. (1999): «Un estudio tipológico de los recursos turísticos», Revista Aragonesa de Administración Pública, $\mathrm{n}^{\circ} 3$, pp. 19-76.

DEL ÁLAMO, E. (2016): «Los espacios de la cultura», en Manual Atalaya de Apoyo a la Gestión Cultural. Cádiz, Universidad de Cádiz y Junta de Andalucía.

DÍAZ, B. (2010): Diseño de productos turísticos. Madrid, Editorial Síntesis.

FERNÁNDEZ, S. y CABALLERO, C. (2004): «Patrimonio industrial en Madrid. Intervención arqueológica en la fábrica de gas de Puerta Toledo», Estudios de Prehistoria y Arqueología Madrileñas, $\mathrm{n}^{\circ}$ 13, pp. 119-130.

HIDALGO, C. y PALACIOS, A. (2016): «El patrimonio industrial declarado Bien de Interés Cultural en Madrid. Su integración en la oferta cultural y turística de la ciudad», Pasos. Revista de Turismo y Patrimonio Cultural, vol. 14 (1), pp. 193-212. 
JUNTA DE ANDALUCÍA (2006): Cartografía Cultural. Equipamientos de Cádiz y Tetuán: metodología de elaboración. Sevilla. Consejería de Cultura de la Junta de Andalucía.

LENO, F. (1993): Técnicas de evaluación del potencial turístico. Madrid, MICYT.

LLURDÉS I COIT, J. (1999): «Patrimonio industrial y patrimonio de la humanidad. El ejemplo de las colonias textiles catalanas. Potencialidades turísticas y algunas reflexiones», Boletín de la Asociación de Geógrafos Españoles, n 28, pp. 147-160.

LÓPEZ, D. (1998): La ordenación y planificación integrada de los recursos territoriales turísticos. Castellón, Universidad Jaume I.

LÓPEZ, M. y CANDELA, P. (2002): «Patrimonio, cultural y sostenibilidad: el IPICAM (Inventario del Patrimonio Industrial de la Comunidad de Madrid)», en I Congreso de Ingeniería Civil, Territorio y Medio Ambiente, vol. II, pp. 509-520.

MINISTERIO DE MEDIO AMBIENTE (2003): Sistema español de indicadores ambientales de turismo. Madrid, Centro de Publicaciones del Ministerio de Medio Ambiente.

OLIVARES, S. (2013): «Antonio Palacios y el ferrocarril metropolitano», en Paisajes culturales, patrimonio industrial y desarrollo regional. Gijón, CICEES, pp. 433-439.

ORGANIZACIÓN MUNDIAL DEL TURISMO (1995): Lo que todo gestor turístico debe saber. Guía práctica para el desarrollo y uso de indicadores de turismo sostenible. Madrid, OMT.

PARDO, C. (2004): Vaciado industrial y nuevo paisaje urbano en Madrid. Antiguas fábricas y renovación de la ciudad. Madrid, Ediciones La Librería.

PARDO, C. (2006): «El patrimonio industrial urbano de Madrid», Revista Urbano, $\mathrm{n}^{\circ} 15$, pp. 53-63.

PARDO, C. (2014): «Indicadores de sostenibilidad turística aplicados al patrimonio industrial y minero: evaluación de resultados en algunos casos de estudio», Boletín de la Asociación de Geógrafos Españoles, n 65, pp. 11-36.

REVILLA, F. y RAMOS, R. (2008): La arquitectura industrial de Madrid. Madrid, Editorial La Librería.

SANCHO, A. y GARCÍA, G. (2006): «¿Qué indica un indicador? Análisis comparativo en los destinos turísticos», Revista de Análisis Turístico, $\mathrm{n}^{\circ}$ 2, $2^{\circ}$ semestre, pp. 69-85.

VALENZUELA, M. (2001): «Turismo y servicios recreativos», en Estructura Económica de Madrid (2 ${ }^{\text {a }}$ Ed.). Madrid, Biblioteca CIVITAS Economía y Empresa, pp. 605-649.

VALENZUELA, M.; PALACIOS, A. e HIDALGO, C. (2008): «La valorización turística del patrimonio minero en entornos rurales desfavorecidos: actores y experiencias», Cuadernos de Turismo, $\mathrm{n}^{\circ}$ 22, pp. 231-260.

VALENZUELA, M. (2010): «La planificación territorial de la Región Metropolitana de Madrid. Una asignatura pendiente», Cuadernos Geográficos de la Universidad de Granada, no 47 (2), pp. 95-129.

\section{DOCUMENTOS CONSULTADOS}

Plan Estratégico de Cultura de Madrid -PECAM- (2012-2015) Disponible en. http://www. madrid.es/UnidadWeb/Contenidos/EspecialInformativo/TemaCulturaYOcio/Cultura/ PECAM/HaciaPECAM/Ficheros/Pdf_completo_20812ok.pdf 
Plan Estratégico de Turismo. Ciudad de Madrid (2012-2015) Disponible en. http:// www.aept.orguploaded/1\%20PLAN\%20ESTRATEGICO\%20CIUDAD\%20DE\%20 MADRID.pdf?PHPSESSID=957dfab6e8a2d2ec6aba53d560f3a839

Revisión del Plan Nacional de Patrimonio Industrial (2011) Disponible en http://ipce.mcu. es/pdfs/PN_PATRIMONIO_INDUSTRIAL.pdf

\section{WEBGRAFÍA}

Asociación de Operadores Turísticos de Turismo Industrial (AOTI) Disponible en: http:// aoti.es

Portal de Turismo de España. Disponible en: www.spain.info.es

Red Española de Turismo Industrial (RETI). Disponible en: http://www.turismoindustrial.es Región of Madrid. Disponible en: www.turismomadrid.es

Sala Cuarta Pared. Disponible en: www.salacuartapared.es

TICCIH. 100 Elementos del patrimonio industrial en España. Disponible en: http:// www.100patrimonioindustrial.com/Fichas.aspx

Web del Ayuntamiento de Madrid. Disponible en: www.esmadrid.com

Xarxa de Turisme Industrial de Catalunya (XATIC). Disponible en: www.xatic.cat 
